\title{
A gene with major phenotypic effects as a target for selection vs. homogenizing gene flow
}

\author{
JOOST A. M. RAEYMAEKERS, ${ }^{*}+$ NELLIE KONIJNENDIJK, ${ }^{*}$ MAARTEN H. D. LARMUSEAU, $+\S$ \\ BART HELLEMANS, * LUC DE MEESTER $\|$ and FILIP A. M. VOLCKAERT* \\ *Laboratory of Biodiversity and Evolutionary Genomics, University of Leuven, Ch. Deberiotstraat 32, Leuven B-3000, Belgium, \\ $\uparrow$ Zoological Institute, University of Basel, Vesalgasse 1, Basel CH-4051, Switzerland, $\$$ Laboratory of Forensic Genetics and \\ Molecular Archaeology, Department of Forensic Medicine, UZ Leuven, Kapucijnenvoer 33, Leuven B-3000, Belgium, \\ $\S$ Department of Imaging and Pathology, University of Leuven, Campus Gasthuisberg, Herestraat 49, Leuven B-3000, Belgium, \\ qLaboratory of Aquatic Ecology, Evolution and Conservation, University of Leuven, Ch. Deberiotstraat 32, Leuven B-3000, \\ Belgium
}

\begin{abstract}
Genes with major phenotypic effects facilitate quantifying the contribution of genetic vs. plastic effects to adaptive divergence. A classical example is Ectodysplasin $(E d a)$, the major gene controlling lateral plate phenotype in three-spined stickleback. Completely plated marine stickleback populations evolved repeatedly towards low-plated freshwater populations, representing a prime example of parallel evolution by natural selection. However, many populations remain polymorphic for lateral plate number. Possible explanations for this polymorphism include relaxation of selection, disruptive selection or a balance between divergent selection and gene flow. We investigated 15 polymorphic stickleback populations from brackish and freshwater habitats in coastal North-western Europe. At each site, we tracked changes in allele frequency at the Eda gene between subadults in fall, adults in spring and juveniles in summer. Eda genotypes were also compared for body size and reproductive investment. We observed a fitness advantage for the Eda allele for the low morph in freshwater and for the allele for the complete morph in brackish water. Despite these results, the differentiation at the Eda gene was poorly correlated with habitat characteristics. Neutral population structure was the best predictor of spatial variation in lateral plate number, suggestive of a substantial effect of gene flow. A meta-analysis revealed that the signature of selection at Eda was weak compared to similar studies in stickleback. We conclude that a balance between divergent selection and gene flow can maintain stickleback populations polymorphic for lateral plate number and that ecologically relevant genes may not always contribute much to local adaptation, even when targeted by selection.
\end{abstract}

Keywords: dispersal, fitness, migration, polymorphism, reproduction, threespine

Received 28 July 2013; revision received 20 October 2013; accepted 28 October 2013

\section{Introduction}

Both selective processes, such as natural selection, and selectively neutral processes, such as random gene flow and genetic drift, shape natural diversity (Kimura 1983; Endler 1986; Schluter 2000; Edelaar \& Bolnick 2012). Divergent selection is thought to enhance adaptive

Correspondence: Joost Raeymaekers, Fax: +32 163245 75; E-mail: joost.raeymaekers@bio.kuleuven.be divergence between populations from different environments, while high gene flow is expected to have a constraining effect on this differentiation. Hence, adaptive divergence proceeds as a function of the balance between both forces. This has been suggested by theoretical work (Levene 1953; Endler 1977; Slatkin 1985; García-Ramos \& Kirkpatrick 1997; Hendry et al. 2001) as well as empirical studies (reviewed in Räsänen \& Hendry 2008; Pinho \& Hey 2010). Most of these studies have been focusing on adaptive divergence at the 
phenotypic level, because selection acts on phenotypes regardless of their genetic basis. However, the evolutionary response to selection is determined by the underlying genetic architecture of the phenotype, as well as by the strength of gene flow which can counteract frequency changes for the genes that matter for the phenotype (Lenormand 2002). The genetic level thus enhances our understanding of adaptive divergence. It makes it feasible to assess the contribution to adaptive divergence of selection favouring one allele over another, as well as the homogenizing effect of gene flow.

Including the genetic level in studies of adaptive divergence may be accomplished by a combination of field studies describing patterns of adaptive divergence, genomic studies pinpointing to the genetic basis of the traits involved and experiments identifying the fitness consequences arising from the phenotypic effects of specific alleles in a simplified ecological context. Considerable progress in each aspect has been made in the study of the evolution of lateral armour plates in threespined sticklebacks (Gasterosteus aculeatus L., Gasterosteidae, Teleostei; reviewed in Barrett 2010). Lateral plate number represents an important ecological trait with a relatively simple genetic basis. Plate variation has been shown to be controlled by Ectodysplasin (Eda), a major effect gene, along with several minor effect genes (Colosimo et al. 2005). Two alleles, $E d a^{\mathrm{C}}$ and $E d a^{\mathrm{L}}$, account for complete and low plate number, respectively. Completely plated, ancestral sticklebacks inhabit marine and estuarine habitats throughout the Northern Hemisphere. Multiple freshwater populations, characterized by reduced plate number, have evolved postglacially in parallel in a relatively short period of 10000 16000 years (Bell 2001; Raeymaekers et al. 2005). Plate variation has been attributed to a number of abiotic and biotic conditions, including large-scale climatic effects, salinity and calcium levels, variation in water flow and predation pressure (Barrett 2010).

A number of field experiments have started to explore the fitness consequences of allelic variation at $E d a$, pinpointing to some of the functional mechanisms responsible for the evolution of reduced armour in freshwater populations (Barrett et al. 2008, 2009; Marchinko 2009; Zeller et al. 2012a). For instance, there is evidence that in freshwater, sticklebacks carrying the $E d a^{\mathrm{L}}$ allele have a growth advantage leading to higher survival rates and reproductive output (Barrett et al. 2008). This hypothesis was inspired by evidence for differences in length growth between plate morphs (Marchinko \& Schluter 2007). Barrett et al. (2008) initiated their experiment by introducing adult marine sticklebacks heterozygous at the Eda locus to four freshwater ponds. These fish produced juveniles of which length growth and Eda allele and genotype frequencies were tracked year round. After one generation, they observed a net increase in the $E d a^{\mathrm{L}}$ frequency. From a set of welldocumented introductions of completely plated stickleback in freshwater ponds and lakes, it is known that populations can evolve low plate number in less than twenty years, which is less than or equal to 20 generations (Kristjansson et al. 2002; Bell et al. 2004; Le Rouzic et al. 2011; Bell \& Aguirre 2013). This implies that the fitness advantage of the $E d a^{\mathrm{L}}$ allele in freshwater may be considerable.

Despite these results, selection on the Eda locus and the number of lateral plates in nature seems variable and more complex than in semi-natural ponds or isolated lakes. For instance, Zeller et al. (2012b) observed disruptive rather than divergent selection at the Eda locus in a freshwater stream, while no evidence for selection on Eda was found in a nearby freshwater pond. In addition, stickleback habitats such as the open sea, estuaries, lagoons, streams and lakes are often well connected. Although there is sometimes evidence for reproductive isolation even between adjacent marine and freshwater populations (Hagen 1967; Jones et al. 2006; Bell et al. 2010), high gene flow between such environments might occur as well, weakening the response to selection (Baumgartner \& Bell 1984; Bell 2001; McKinnon \& Rundle 2002; Hendry et al. 2009). Clearly, it is important to understand the effect of variety in selection conditions and gene flow on lateral plate divergence. In fact, although the reduction in body armour in freshwater populations compared to marine populations is very common across the stickleback's distribution range, it is not the only pattern observed. Several freshwater populations remain completely plated or evolve only weak armour reduction (Hagen \& Gilbertson 1972; Hagen \& Moodie 1982; Baumgartner \& Bell 1984; Banbura 1994; Klepaker 1995; Bell 2001; McCairns \& Bernatchez 2008, 2012; Berner et al. 2010; Lucek et al. 2010; Leinonen et al. 2012; Moser et al. 2012), or might even show reverse evolution for plate number (Kitano et al. 2008). Likewise, marine and estuarine populations may be highly variable in plate number as well (Banbura 1994; Klepaker 1996; Raeymaekers et al. 2007). Overall, there is a bias in the literature towards several prominent studies on stickleback investigating sharp contrast divergence between completely plated marine and low-plated resident freshwater populations (e.g. Cresko et al. 2004; Colosimo et al. 2005; Barrett et al. 2008; Schluter \& Conte 2009; Jones et al. 2012), mostly from Northern Europe and the Pacific Coast of North America, while vast regions in Western and Central Europe and the Atlantic Coast of North America show weaker contrasts (e.g. Münzing 1963; Hagen \& Moodie 1982; Raeymaekers et al. 2007; McCairns \& Bernatchez 2008; Lucek et al. 2010). 
In this study, we aim to explore the effects of variation in selection conditions and gene flow on the dynamics of the Eda locus in natural stickleback populations. An excellent system in this respect can be found in the estuaries and coastal lowlands of North-western
Europe (Fig. 1; Heuts 1947; Raeymaekers et al. 2005, 2007, 2012). Populations in this area are all polymorphic for plate number. We here start from the observation that these populations occur in freshwater as well as brackish water. A number of mechanisms, including

(a)

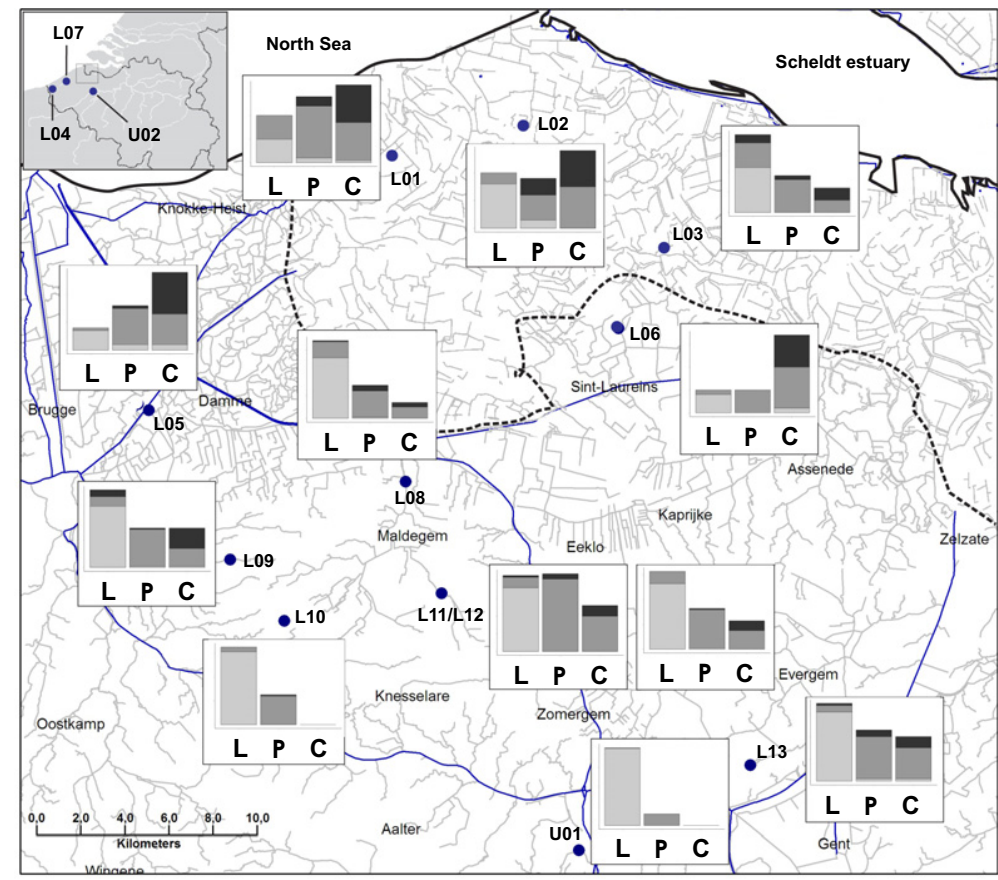

L04

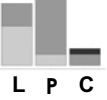

L07

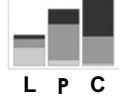

U02

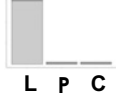

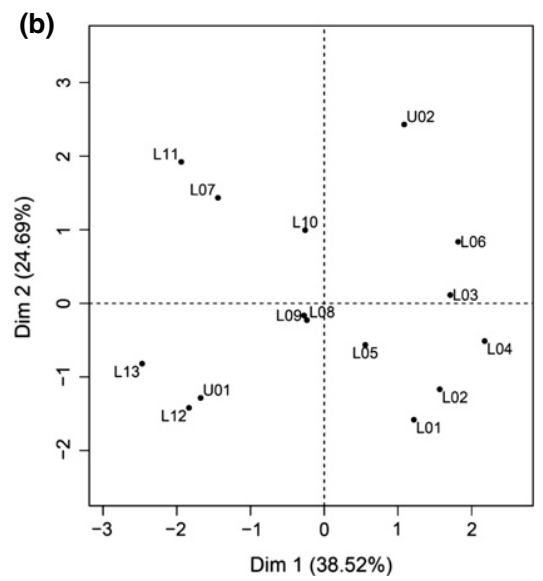

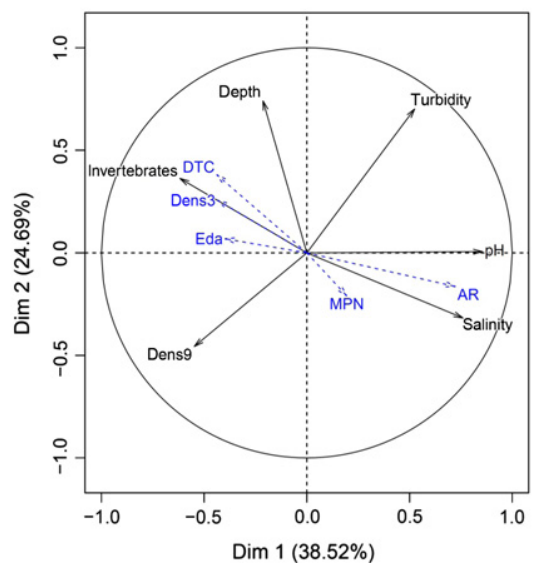

Fig. 1 (a) Locations and characteristics of 15 polymorphic stickleback populations from the Belgian-Dutch lowlands, investigated between spring 2008 and fall 2010. The bar charts show the relative plate morph frequencies in every site (L, low-plated individuals; $\mathrm{P}$, partially plated individuals; $\mathrm{C}$, completely plated individuals). The proportion of homozygotes for the Eda allele (LL), heterozygotes (CL) and homozygotes for the $E d a^{\mathrm{C}}$ allele $(C C)$ is shaded in light grey, dark grey and black, respectively. (b) Individual factors map (left) and variable factors map (right) of a principal component analysis on habitat characteristics of the 15 sampling sites. Variables labelled in black (full arrows) were used to calculate the principal components; variables in blue (dotted arrows) were included as supplementary variables. Dens3: density of three-spined stickleback. Dens9: density of nine-spined stickleback. Eda: frequency of the Eda allele for the low morph. MPN: mean plate number. Invertebrates: density of macro-invertebrate predators. DTC, distance to the coast. AR, allelic richness at neutral markers. Population codes as in Table 1. 
time since divergence, genetic constraints, balancing selection (including overdominance and negative frequency dependent selection), relaxation of selection, environmental heterogeneity and a balance between divergent selection and gene flow, may explain why populations remain polymorphic for ecologically relevant traits (Endler 1973, 1977; Forsman \& Shine 1995; Joron et al. 1999; Merilaita 2001; Brooks 2002; Hoekstra et al. 2004; Larmuseau et al. 2010). Here, we hypothesize that a balance between divergent selection and gene flow maintains the polymorphism for plate number. Indeed, divergent selection pressures may be present (e.g. related to salinity), but adaptive divergence may be hampered by subadaptive or maladaptive gene flow. Considerable gene flow among local stickleback populations seems likely, because part of the study area is well connected through a dense network of water bodies (Fig. 1). Moreover, some populations might be anadromous, facilitating gene flow upon spawning migrations between brackish and freshwater in spring (Tudorache et al. 2007). The combined effect of divergent selection vs. homogenizing gene flow might as well shape phenotypic distributions at the landscape level (Endler 1973, 1977; Bell \& Richkind 1981; Bell 1982; Baumgartner 1986; Moore et al. 2007).

To test the selection - gene flow scenario, we selected 15 polymorphic populations from a range of brackish and freshwater habitats and investigated the dynamics of the Eda gene from spring 2008 until fall 2010. We first tested for environment-fitness correlations (indicative for selection; Endler 1986) by comparing populations from different salinities for changes in Eda allele frequencies between life stages and by comparing Eda genotypes for body size, reproductive investment and reproductive success. We then quantified gene flow between all populations using microsatellite markers. The strength of selection on the Eda gene relative to the strength of gene flow was compared with standard tests for genomic signatures of selection. Finally, we performed a meta-analysis to compare the relative contribution of divergent selection vs. gene flow to variation in plate number and allelic variation at the Eda gene across various spatial scales.

\section{Material and methods}

\section{Study area}

Three-spined sticklebacks from the coastal lowlands of Belgium and the Netherlands are either anadromous or landlocked and live in ponds, ditches, small streams, estuaries or polder creeks (Wootton 1976; Raeymaekers et al. 2005, 2007). The area contains diked brackish and freshwater habitats of Holocene origin with varying connectivity to adjacent estuaries and the open sea. Habitats are usually shallow $(<1.5 \mathrm{~m})$. The water current is slow to stagnant. Three-spined and nine-spined sticklebacks (Pungitius pungitius L.) dominate the fish community. The three-spined stickleback populations contain varying percentages of the three plate morphs as defined by Ziuganov (1983), that is the low-plated morph (10 or fewer plates), the partially plated morph (11-20 plates) and the completely plated morph (more than 20 plates). Populations that are $100 \%$ low plated do occur outside the study area, in rivers and streams further inland (Raeymaekers et al. 2008, 2009).

\section{Field sampling and morphology}

We selected 15 sites, including six brackish creeks, two freshwater ponds, four freshwater ditches and three freshwater streams (Table 1; Fig. 1). Each of the sites was visited twice in spring, twice in summer and twice in fall (spring 2008, fall 2008, spring 2009, summer 2009, summer 2010 and fall 2010). Droughts in the summer of 2010 and inundations in the fall of 2010 prohibited sampling some of the sites. Fieldwork started with monitoring the water for temperature $\left({ }^{\circ} \mathrm{C}\right), \mathrm{pH}$, conductivity ( $\mu \mathrm{S} / \mathrm{cm}$; for analyses converted to salinity in psu) and oxygen (mg/L) using a Hach field-monitoring unit (Hach, Loveland, Co, USA). An index for the turbidity of the water was obtained with a Sneller tube. The water depth was calculated as the median depth $(\mathrm{cm})$ of five equidistant points along a stretch of $100 \mathrm{~m}$ of the water body. A single person (JAMR) then sampled three-spined and nine-spined sticklebacks by progressively dipnetting along the same stretch of $100 \mathrm{~m}$ with approximately one dip per metre, each time using the same hand net. This method enabled us to estimate the density of three-spined and nine-spined sticklebacks as the number of individuals per metre. While fishing, the total density of macro-invertebrate predators of stickleback was determined as well by counting all backswimmers (Notonecta glauca), dragonfly larvae (Anax sp. and Aeschna sp.) and great diving beetles (Dytiscus marginalis). Sticklebacks were immediately anaesthetized and flash frozen in dry ice after capture. In spring 2009, an additional sampling was performed to search for predatory fishes such as perch, eel and pike. We here used electrofishing in freshwater and a seine net in brackish water. The sticklebacks captured on this occasion were excluded from all analyses.

In the laboratory, the sticklebacks were thawed on ice, measured (standard length (SL); $\pm 0.1 \mathrm{~cm}$ ), weighed ( $\pm 0.01 \mathrm{~g})$, photographed and fin-clipped. Spring-caught samples were assessed visually for any external signs of reproductive investment. Reproductive males were identified based on the characteristic red coloration of 
166 J. A. M. RAEYMAEKERS ET AL.

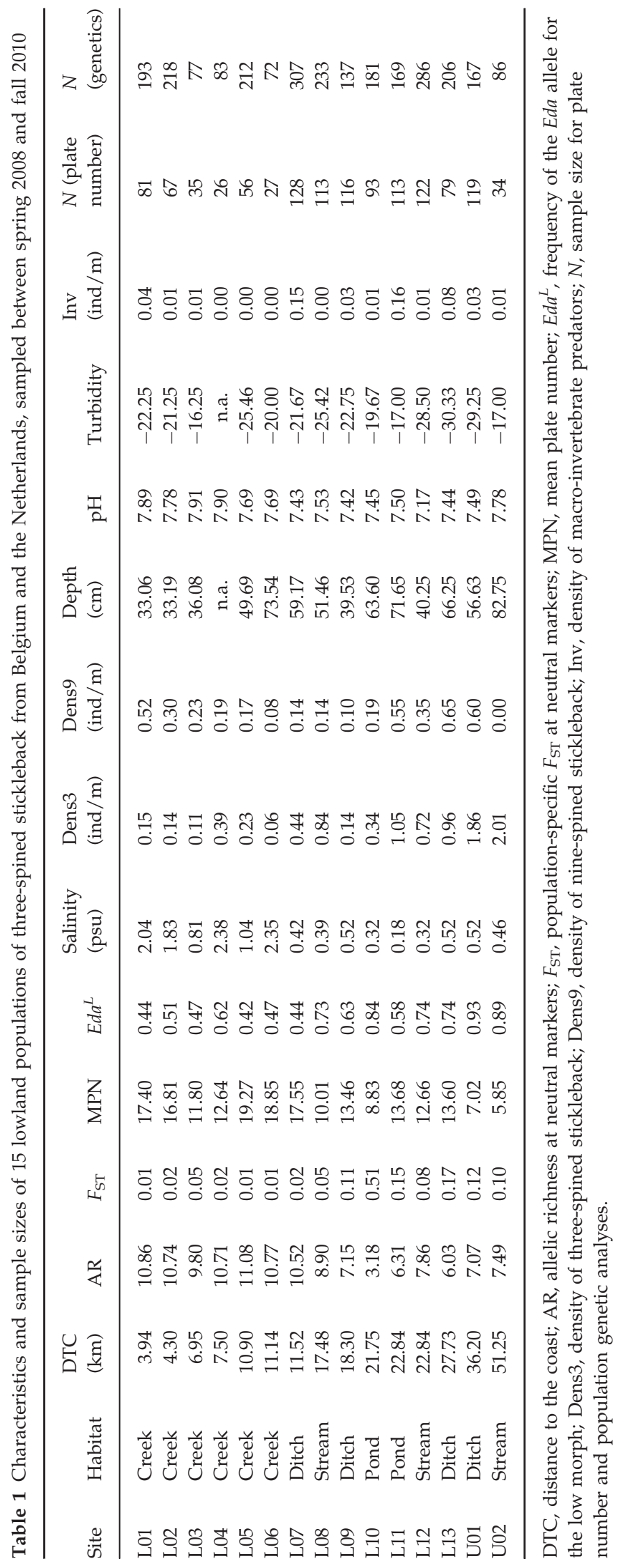


the throat, while reproductive females were identified based on the development of eggs. Individuals smaller than $25 \mathrm{~mm}$ SL were preserved in 100\% ethanol, while larger individuals were stored on a $4 \%$ formalin solution. After 2 months, a subsample of the formalinstored fish was rinsed with water for $72 \mathrm{~h}$, bleached for $4 \mathrm{~h}$ ( $1 \% \mathrm{KOH}$ bleach solution) and stained with alizarin red $\mathrm{S}$ to facilitate plate counts and plate morph registration (Taylor \& Van Dyke 1985). After staining, the number of lateral plates on the left side was determined. Based on this number, specimens were categorized as low-plated, partially plated or completely plated, as defined above. The presence of a keel, a small modification of the caudal lateral plates, was noted, but not included in the plate count.

\section{DNA extraction and genotyping}

Genomic DNA was extracted from fin clips using the Nucleospin 96 Tissue DNA Extraction kit (MachereyNagel) according the manufacturer's protocol. Allelic variation was assessed at 15 microsatellite loci and one locus (STN380) linked to the Eda gene (Peichel et al. 2001; Colosimo et al. 2005; Mäkinen et al. 2008) divided over 2 multiplex reactions. Multiplex 1 contained loci Gaest66, STN26, STN30, STN130, STN173, STN174, STN185, STN196 and STN380, while multiplex 2 contained loci Gaest4, STN3, STN23, STN52, STN61, STN148 and STN219. All loci were amplified with the Qiagen ${ }^{\circledR}$ Multiplex PCR Kit (Qiagen, Venlo, the Netherlands). The $10 \mu \mathrm{L}$ PCR cocktail contained 1-100 ng genomic DNA, $0.05 \mu \mathrm{M}$ (STN26, STN130, STN173), $0.1 \mu \mathrm{M}$ (Gaest66, STN3, STN30, STN174, STN185, STN196 and STN219) or $0.2 \mu \mathrm{M}$ (Gaest4, STN23, STN52, STN61, STN148 and STN380) forward and reverse primer, $1 \times$ Qiagen multiplex PCR master mix (3 mM $\mathrm{MgCl}_{2}$ ) and RNase-free water. The reaction consisted of an initial activation step of $15 \mathrm{~min}$ at $95^{\circ} \mathrm{C}$, followed by 26 cycles of $30 \mathrm{~s}$ at $95{ }^{\circ} \mathrm{C}, 90 \mathrm{~s}$ at $53{ }^{\circ} \mathrm{C}$ and $60 \mathrm{~s}$ at $72{ }^{\circ} \mathrm{C}$. A final elongation step of $30 \mathrm{~min}$ at $60^{\circ} \mathrm{C}$ was performed. PCR products were visualized on an ABI3130 Avant Genetic analyzer (Applied Biosystems, Foster City, CA, USA). Allele sizes were determined by means of an internal GeneScan 500-LIZ size standard, and genotypes were obtained using GENEMAPPER 4.0 (Applied Biosystems). Genotypes were checked for scoring errors using MICRO-CHECKER 2.3 (van Oosterhout et al. 2004).

\section{Data analysis}

Analyses aimed at describing (i) habitat characteristics, (ii) population genetic structure and (iii) the variation in lateral plate number and at the Eda gene. We also investigated (iv) signatures of selection on plate number and the Eda gene within populations, and (v) the gene flowselection balance for plate number and Eda at the landscape level. Total sample sizes for plate number and population genetic analysis are provided in Table 1. A schematic overview of the analyses together with sample sizes per Eda genotype per season is provided in Table S1 (Supporting information). Unless mentioned otherwise, analyses were performed in R ( $\mathrm{R}$ Core Team 2012).

Habitat structure. Habitat characteristics included salinity, $\mathrm{pH}$, water depth, the density of nine-spined stickleback, the density of macro-invertebrate predators and turbidity. We first investigated the temporal stability of the biotic and abiotic environment across sites over the entire period (2008-2010). We then performed a principal component analysis on mean values of each of these variables. The first and second principal components were plotted to detect clusters of sites with similar habitat characteristics and to investigate how habitats change with distance to the coast (DTC, measured as the crow flies).

Population genetic structure. First, genetic diversity was calculated as the observed heterozygosity $\left(\mathrm{H}_{\mathrm{O}}\right)$ and as allelic richness (AR; i.e. the number of alleles standardized for sample size and averaged over loci), as implemented in the HIERFSTAT package in R. These metrics were used to test whether or not genetic diversity declines with distance to the coast. Temporal replicates (2008-2010; overview in Table S1, Supporting information) were pooled by site for this purpose. Second, overall and pairwise population differentiation was quantified with the ADEGENET package in $\mathrm{R}$ using the standardized allelic variance $F_{\mathrm{ST}}$. Pairwise $F_{\mathrm{ST}}$ values were used to visualize population structure with a twodimensional classical multidimensional scaling (CMDS) plot with the function cmdscale in $\mathrm{R}$. This was first carried out without pooling the temporal replicates to evaluate the temporal stability of the population structure. Then, all temporal replicates were pooled, allowing for a spatial assessment of population structure. To investigate the temporal stability and spatial structure in more detail, we also performed a test for isolation by distance and a hierarchical analysis of molecular variance (AMOVA) in ARLEQUIN 3.0 (Excoffier et al. 2005) by partitioning the genetic variability into a within-site $\left(\mathrm{F}_{\mathrm{SC}}\right)$ and between-site $\left(\mathrm{F}_{\mathrm{CT}}\right)$ component. Third, for comparison, we also assessed population structure with a Bayesian Markov chain Monte Carlo (MCMC) assignment method based on multilocus genotypes, implemented in STRUCTURE 2.3.3. (Pritchard et al. 2000). The most likely structure was calculated assuming admixture and correlated allele frequencies. Each run, considering 
population structure according to a specific number of groups $(1 \leq K \leq 15)$, consisted of three chains of $10^{5}$ MCMC replicates, initiated by $10^{4}$ burn-in steps. Finally, to quantify migration in the study area, we used a Bayesian clustering method to identify first-generation migrants, implemented in GENECLASS 2.0 (Piry et al. 2004). For each individual, the probability was calculated to belong to the pool of microsatellite-based multilocus genotypes from the site where it was captured. Probability computation was based on Monte Carlo resampling with $10^{3}$ simulated individuals (Rannala \& Mountain 1997), and significance was evaluated at the $5 \%$ level.

Lateral plate number, Eda allele frequencies and migration. First, we investigated the distribution of plate number and the Eda allele frequencies at every site. Second, an ANOVA was used to analyse the occurrence of the $E d a^{\mathrm{L}}$ allele (scored as 0,1 or 2 alleles per individual). Factors in this model included site as a fixed factor and season nested in site as a random factor. Third, correlations between distance to the coast, average plate number and the $E d a^{\mathrm{L}}$ frequency were tested. Finally, for each site, we investigated the association between plate number and Eda on the one hand and migration on the other hand by (i) comparing the probability of migration (see above) among Eda genotypes; (ii) testing the correlation between the probability of migration and plate number; and (iii) comparing plate number between putative migrants and residents.

Signatures of selection within populations. Stickleback is a short-lived species, and the generation time of the investigated populations is presumably annual. Therefore, most individuals within a given season can be assigned to a specific life stage. Spring samples mostly contain adults of 1 year old. Summer samples mostly contain juveniles while adults become scarce, and samples in fall almost exclusively contain subadults. Life stage-specific Eda allele frequencies hence can be quantified, and local shifts in these frequencies might be indicative for an episode of local selection at the Eda gene. If so, it is expected that such shifts are correlated with the local environment. To test this expectation, we tested the correlation between habitat characteristics and the difference in $E d a^{\mathrm{L}}$ frequency between (i) juveniles captured in summer vs. adults captured in the preceding spring; (ii) subadults captured in fall vs. juveniles captured in the preceding summer; and (iii) adults captured in spring vs. subadults captured in the preceding fall. Because these metrics reflect a life stage-specific differential fitness advantage at the Eda gene in terms of (i) reproductive output, (ii) juvenile survival and (iii) subadult overwinter survival, we further refer to these indices as $\Delta E d a[$ reproductive output], $\Delta E d a[j u v e n i l e$ survival] and $\Delta E d a$ [overwinter survival], respectively. For each of these indices, positive values suggest a fitness advantage for the $E d a^{\mathrm{L}}$ allele, while negative values suggest a fitness advantage for the $E d a^{C}$ allele. Pearson correlations between each index and the aforementioned habitat characteristics (mean values of the two subsequent seasons) were calculated and tested for significance. Distance to the coast was included as well, to account for any unmeasured factor correlated with a declining influence of the coastal environment. Explanatory variables with significant or nearly significant effects were included in multiple regressions. Model fit was compared based on the $\mathrm{AIC}_{\mathrm{C}}$ criterion for small sample size. Because $\Delta E d a[$ reproductive output], $\Delta E d a$ [juvenile survival] and $\Delta E d a$ [overwinter survival] might not exclusively reflect differential reproductive output or mortality, but can also be influenced by migration, all computations were done with and without firstgeneration migrants (see above).

To test for additional indications for selection at the $E d a$ gene, we calculated for each site the index $\Delta E d a$ [reproductive investment], that is the difference in $E d a^{\mathrm{L}}$ frequency between individuals that did and did not visibly invested in reproduction (see above). We expected this index to correlate with $\Delta E d a$ [reproductive output], as a shift in $E d a^{\mathrm{L}}$ frequency from one generation (adults in spring) to the next (juveniles in summer) should already be visible in the fraction of adults investing in reproduction. Furthermore, we also compared the three Eda genotypes for differences in body size at the juvenile (summer), subadult (fall) and adult (spring) stage, to test for a potential growth advantage associated with the Eda gene. For juveniles, this test result might as well reflect an age advantage arising from faster maturation of the parents. This analysis was performed with general linear models (one per life stage) with standard length as the dependent variable and site, Eda genotype and the site by Eda genotype interaction as independent variables. For adults in spring, sex was also included in the model. Sampling year was included as a random block factor.

Selection vs. gene flow. Four methods (I-IV) were used to quantify the relative contribution of selection and gene flow to the differentiation in plate number and at the Eda gene. (I) Outlier detection tests implemented in LOSITAN (Antao et al. 2008) and BAYESCAN (Foll \& Gaggiotti 2008) were used to evaluate whether the global $F_{S T}$ at the Eda locus classified as a non-neutral outlier (indicative of selection) as compared to the microsatellite markers. A false discovery rate of 0.05 was applied for both methods. (II) Likewise, a $F_{\mathrm{ST}}-\mathrm{P}_{\mathrm{ST}}$ approach (Raeymaekers et al. 2007; Leinonen et al. 2008) was used to 
investigate whether the global differentiation in plate number $\left(\mathrm{P}_{\mathrm{ST}}\right.$ [plates]) exceeded the global neutral genetic differentiation as quantified with microsatellite markers. (III) Correlation analysis and multiple regressions were used to explain the interpopulation variation in average plate number and the $E d a^{\mathrm{L}}$ frequency. Explanatory variables included the aforementioned habitat characteristics (mean values over the entire period). Populationspecific $F_{\mathrm{ST}}$ (as calculated in GESTE; Foll \& Gaggiotti 2006) and allelic richness were included as well, to evaluate whether phenotypic variation (plate number) and the underlying genetic variation $(E d a)$ are associated with neutral genetic processes. As above, explanatory variables with significant or nearly significant simple effects were included in multiple regressions, of which the model fit was compared based on the $\mathrm{AIC}_{\mathrm{C}}$ criterion for small sample size. (IV) Simple and partial Mantel tests on population pairs were used to identify the determinants of pairwise differentiation at the Eda locus $\left(F_{\mathrm{ST}}[E d a]\right)$, as well as pairwise differentiation in plate number $\left(\mathrm{P}_{\mathrm{ST}}[\right.$ plates]). Explanatory variables included pairwise differentiation $\left(F_{\mathrm{ST}}\right)$ at neutral markers as well as pairwise Euclidean distances based on habitat characteristics. For each of these analyses (I-IV), one population (L10) was excluded as its extremely low genetic diversity suggested that it might have been introduced or gone through a recent bottleneck, and hence, might be not in selection-migration-drift balance with the surrounding populations.

\section{Meta-analysis}

A meta-analysis of the relative strength of selection targeting the Eda locus vs. homogenizing gene flow was performed to compare our results on the lowland populations with five other studies (Raeymaekers et al. 2007; Mäkinen et al. 2008; Van Dongen et al. 2009; DeFaveri et al. 2011; DeFaveri \& Merilä 2013). These studies were performed on natural populations of three-spined sticklebacks sampled across various spatial scales (Table 2). Populations were either selected along a salinity cline, or chosen from a set of discrete habitats with different salinities (Table 2). All data sets included plate number (except for the study by DeFaveri et al. 2011), neutral genetic markers and markers linked to the Eda gene (STN365, STN380 or STN381). On one occasion, only plate number and neutral genetic data have been published (Van Dongen et al. 2009), but Eda genotypes of the same populations were available.

Each data set was analysed in parallel with the lowland data set according to analyses I to IV, as outlined above. The results of analysis I (outlier tests with LOSITAN and BAYESCAN) and analysis II ( $F_{\mathrm{ST}}-P_{\mathrm{ST}}$ comparisons) were summarized across studies with a linear regression analysis regressing global values for $F_{\mathrm{ST}}[E d a]$ and $P_{\text {ST }}$ [plates] on global values for neutral $F_{\mathrm{ST}}$. Analysis III consisted of testing correlations between neutral genetic diversity on the one hand and average plate number and the $E d a^{\mathrm{L}}$ frequency on the other hand. For analysis IV, correlations between pairwise differentiation at neutral genetic markers (pairwise $F_{\mathrm{ST}}$ ), pairwise differentiation at the Eda locus (pairwise $F_{\mathrm{ST}}[E d a]$ ) and pairwise differentiation in plate number were computed. For two data sets that also contained detailed salinity data (i.e. the current study and the Baltic Sea study by DeFaveri \& Merilä 2013), correlations with salinity were calculated as well.

\section{Results}

\section{Habitat structure}

Abiotic and biotic characteristics, averaged over the period 2008-2010, are presented in Table 1. Overall, sites differed significantly in salinity $\left(F_{14,26}=8.50 ; \quad P\right.$ $<0.0001)$, $\mathrm{pH}\left(F_{14,26}=3.97 ; P=0.0012\right)$ and water depth $\left(\mathrm{F}_{13,25}=8.19 ; P<0.0001\right)$. Local fluctuations in environmental conditions were small (in particular for salinity) or could be attributed to seasonal effects (such as rainfall) affecting the entire region. Salinity ranged between 0.18 and $2.38 \mathrm{psu}$ and declined with distance from the coast $(R=-0.59 ; P=0.0201)$. Values for $\mathrm{pH}$ were correlated with salinity $(R=0.69 ; P=0.0043)$. Other habitat characteristics did not significantly correlate with salinity, and only water depth was significantly correlated with distance to the coast as well $(R=0.66 ; P=0.0104)$. Six sites had brackish water (L01-L06; equivalent of conductivity values $>1000 \mu \mathrm{S} / \mathrm{cm}$ ) and clustered along the first axis of a principal component analysis (Fig. 1). The remaining sites had freshwater (conductivity values $<1000 \mu \mathrm{S} / \mathrm{cm}$ ). These sites had more heterogeneous PC values, reflecting either a high density of macro-invertebrate predators (L07, L11), a high density of nine-spined sticklebacks (L12, L13, U01) or a high turbidity (U02). Predatory fishes included eel (Anguilla anguilla L.; observed occasionally at L08 and L12) and perch (Perca fluviatilis L.; common at L06).

\section{Population genetic structure}

Genetic diversity, quantified as allelic richness, declined with distance from the coast $(R=-0.75 ; P=0.0021$; Fig. 2). AMOVA revealed significant genetic structure among sites $\left(F_{\mathrm{CT}}=0.046 ; P<0.0001\right)$ and, albeit much weaker, among temporal replicates within sites $\left(F_{\mathrm{SC}}=0.003 ; P<0.0001\right.$; Fig. S1, Supporting information). A CMDS plot based on pairwise $F_{\mathrm{ST}}$ revealed clustering of the sites near the coast, including those 
170 J. A. M. RAEYMAEKERS ET AL.

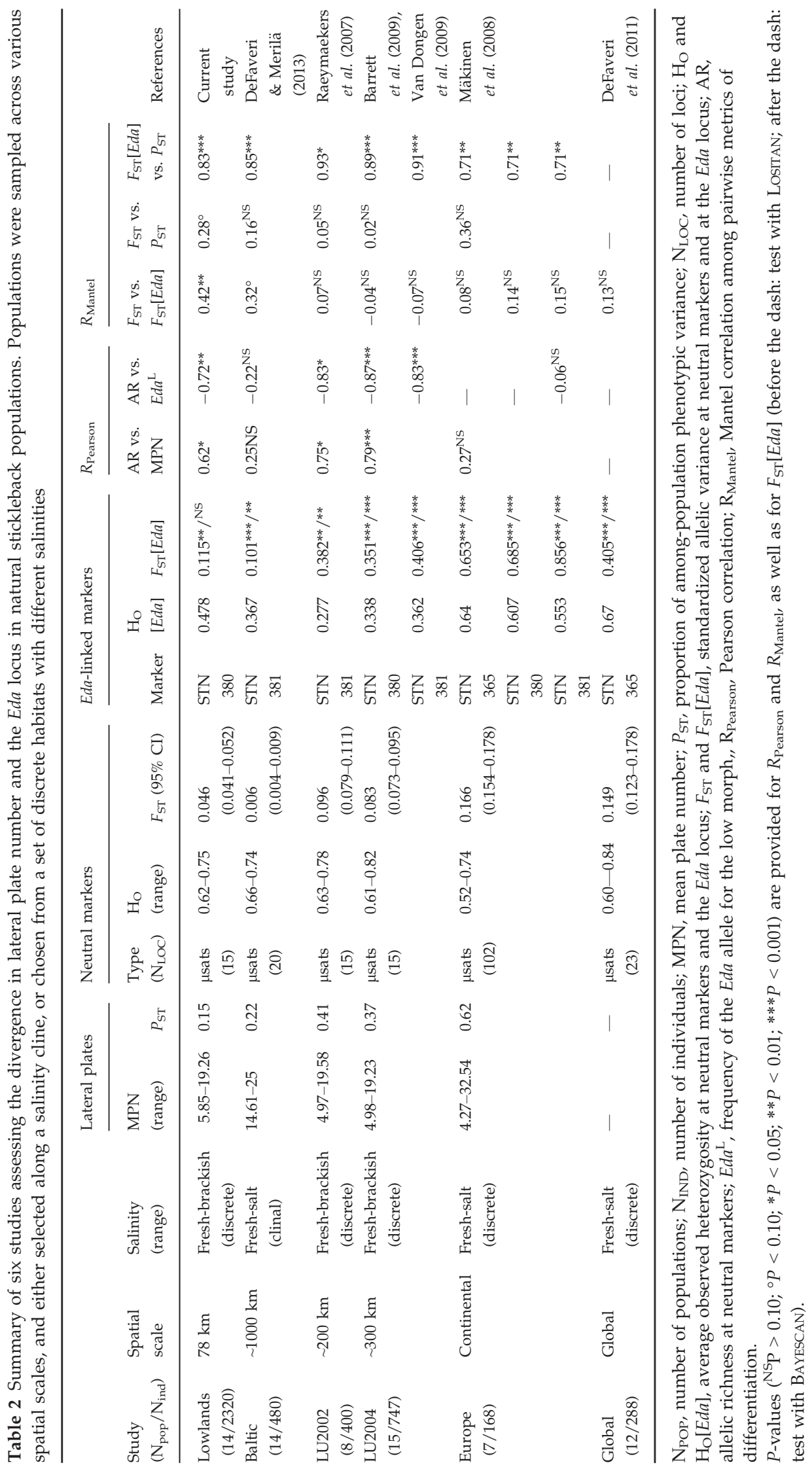


(a)
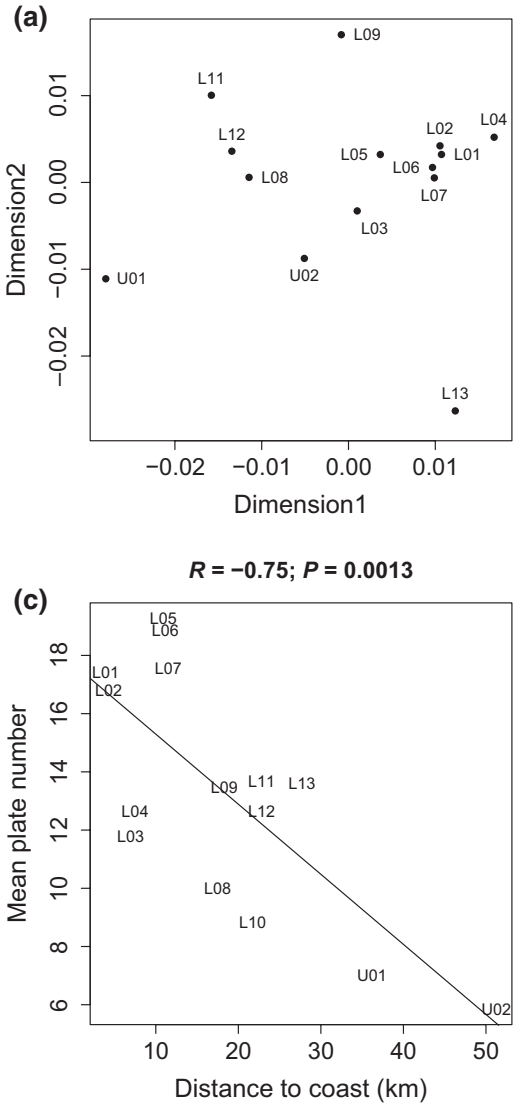
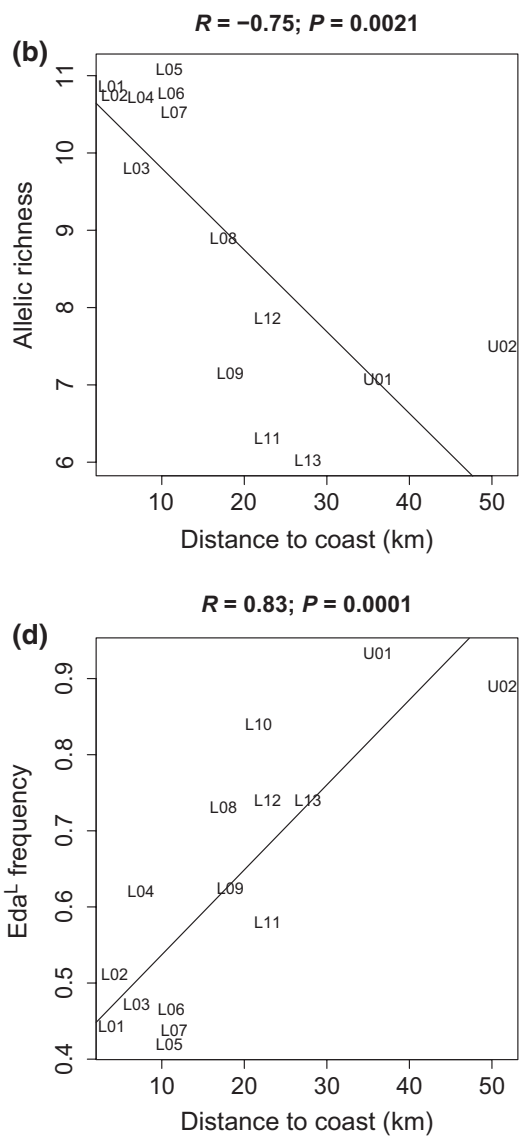

Fig. 2 (a) Classical multidimensional scaling plot of neutral population genetic structure based on pairwise $F_{\mathrm{ST}}$. Correlation between distance to the coast and (b) allelic richness at neutral markers, (c) the average number of lateral plates and (d) the $E d a^{\mathrm{L}}$ frequency. Population codes as in Table 1. Population L10 is excluded from plots $a$ and $b$. that were geographically distant (Fig. 2). Accordingly, the test for isolation by distance was not significant (geographical distance vs. neutral pairwise $F_{\mathrm{ST}}$ : $R=0.11 ; P=0.29$ ). Bayesian analysis with STRUCTURE suggested an optimal structure with seven clusters: two mixing 'coastal' clusters containing individuals from populations L01 to L07, a cluster containing populations L08, L11 and L12, a cluster containing populations U01 and U02, and three clusters containing a single population (L09, L10, L13). The analyses of first-generation migrants revealed that the probability of migration did not correlate with distance to the coast $(R=-0.28$; $P=0.31)$ or salinity $(R=0.24 ; P=0.38)$.

\section{Lateral plate number, Eda allele frequencies and migration}

All sites were polymorphic for plate number (Fig. 1a). In line with previous studies (Raeymaekers et al. 2007; Lucek et al. 2012), the contingency between plate morph (completely plated - partially plated - low-plated) and indel-based Eda genotype (CC: homozygous for $E d a^{\mathrm{C}}$; CL: heterozygous; LL: homozygous for $E d a^{\mathrm{L}}$ ) was good, albeit not perfect (Fig. 1a; see Lucek et al. (2012) for potential causes). Differences in the $E d a^{L}$ frequency between sites as well as fluctuations between seasons are shown in Fig. S2 (Supporting information). ANOVA revealed that the occurrence of the $E d a^{L}$ allele $(0,1$ or 2 times per individual) varied significantly between sites $\left(F_{14,2515}=28.73, P<0.0001\right)$, as well as between seasons within sites $\left(F_{50,2515}=1.62, P=0.004\right)$. At the landscape level, we observed that average plate number declined with distance from the coast $(R=-0.75 ; P=0.0013$; Fig. 2), whereas the $E d a^{\mathrm{L}}$ frequency increased $(R=0.83$; $P=0.0001$; Fig. 2). The analysis of first-generation migrants across and within sites identified no association between Eda genotype and the probability of migration, no correlation between the probability of migration and plate number, and no difference in plate number between putative residents and migrants (results not shown).

\section{Signatures of selection within populations}

$\Delta E d a[$ reproductive output], quantifying the difference in $E d a^{\mathrm{L}}$ frequency between juveniles captured in summer and the corresponding adults captured in the preceding spring, mostly indicated a higher $E d a^{\mathrm{L}}$ frequency in juveniles than in adults in freshwater and a lower $E d a^{\mathrm{L}}$ frequency in juveniles than in adults in brackish (and 
more alkaline) water. As a result, this index was negatively correlated with salinity $(R=-0.61 ; P=0.0269$; Fig. 3) and $\mathrm{pH}(R=-0.56 ; P=0.0471)$. Multiple regression followed by AICc-based model selection failed to determine whether either salinity or $\mathrm{pH}$ was the best predictor of $\Delta E d a$ [reproductive output] (i.e. $\Delta \mathrm{AIC}_{\mathrm{C}}<2$ ). $\Delta E d a[$ reproductive output] was also positively correlated with $\Delta E d a$ [reproductive investment], that is the difference in $E d a^{\mathrm{L}}$ frequency in spring between individuals that did and did not visibly invested in reproduction ( $R=0.63 ; P=0.0208$; Fig. 3 ). This suggests that the shift in $E d a^{\mathrm{L}}$ frequency from one generation to the next was indeed caused by differential investment in reproduction in spring. Neither $\Delta E d a$ [reproductive output] nor $\Delta E d a$ [reproductive investment] were correlated with distance to the coast (Fig. 3) or any other habitat characteristic.

$\Delta E d a[$ juvenile survival], quantifying the difference in $E d a^{\mathrm{L}}$ frequency between subadults in fall and juveniles in the preceding summer, did not correlate with any habitat characteristic or geographical variable. $\Delta E d a$ [overwinter survival], quantifying the difference in $E d a^{\mathrm{L}}$ frequency between adults in spring and subadults in the preceding fall, was positively correlated with $\mathrm{pH}$ ( $R=0.61 ; P=0.0456$; Fig. 3 ), but negatively correlated with distance to the coast $(R=-0.64 ; \quad P=0.0333$; Fig. 3). Multiple regression followed by AICc-based model selection failed to determine whether either distance to the coast or $\mathrm{pH}$ was the best predictor of this index (i.e. $\triangle \mathrm{AIC}_{\mathrm{C}}<2$ ).

In summary, shifts in $E d a^{\mathrm{L}}$ frequencies between adults in spring and juveniles in the subsequent summer were negatively correlated with salinity and $\mathrm{pH}$ and positively correlated with differential reproductive investment. Shifts in $E d a^{\mathrm{L}}$ frequencies between subadults in fall and adults in the subsequent spring were positively correlated with $\mathrm{pH}$ (and were hence in the opposite direction), but were also correlated with distance to the coast. All of the above results were confirmed when the analyses were repeated without first-generation migrants (results not shown). Furthermore, we did neither observe significant effects of Eda genotype, nor an Eda genotype by site interaction effect when comparing body size at the juvenile (summer), subadult (fall) or adult stage (spring; Fig. S3, Supporting information). (a)

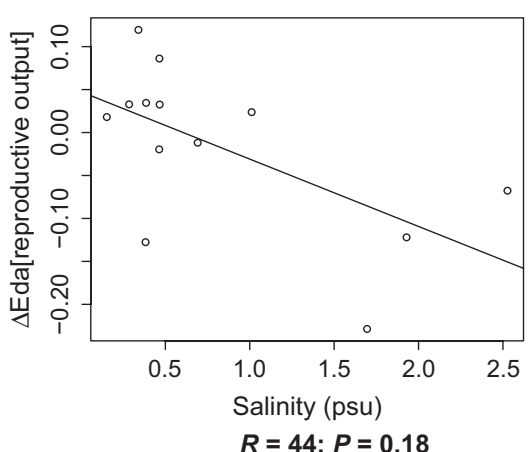

(d)

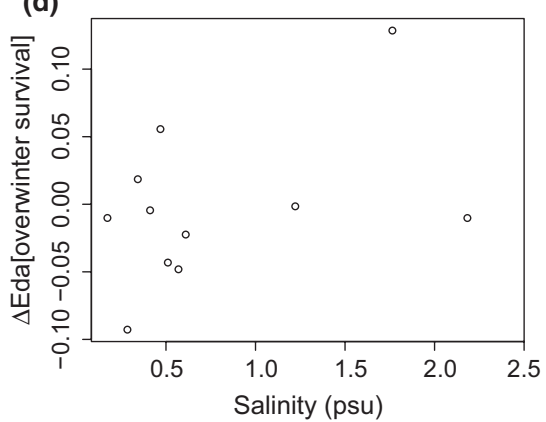

(b)

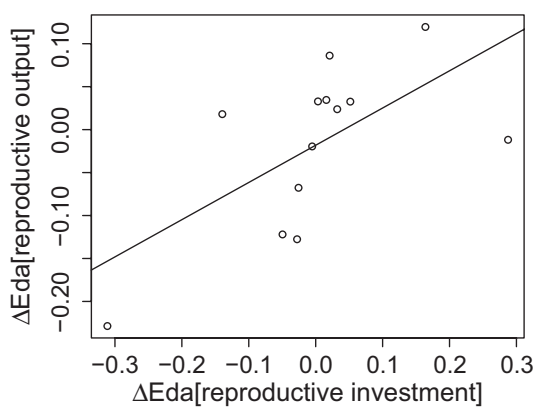

$R=0.61 ; P=0.0456$

(e)

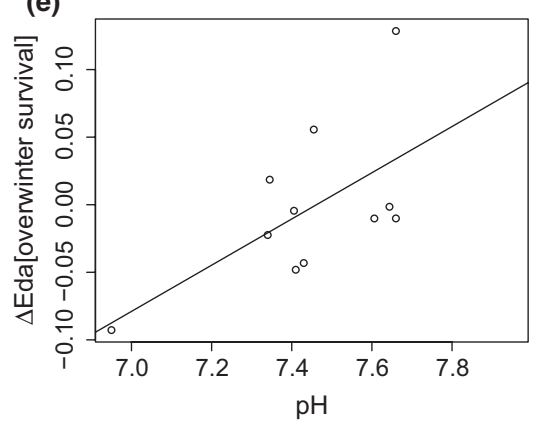

(c)

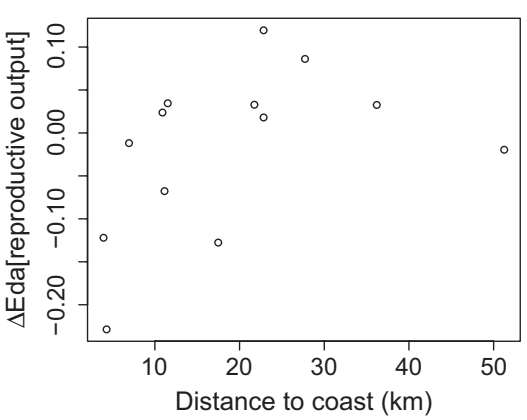

(f)

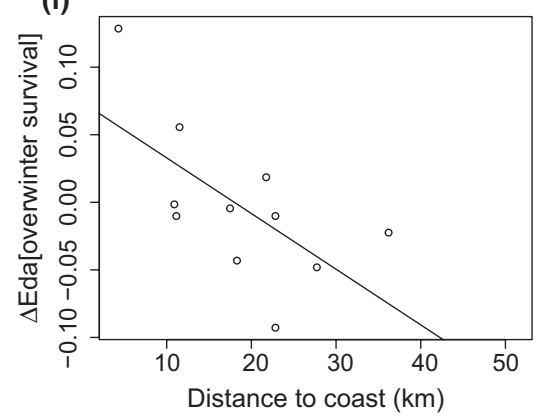

Fig. 3 Correlations between habitat characteristics, distance to the coast, $\Delta E d a[$ reproductive output], $\Delta E d a[$ reproductive investment] and $\Delta E d a\left[\right.$ overwinter survival]. $\Delta E d a\left[\right.$ reproductive output] is the difference in $E d a^{\mathrm{L}}$ frequency between juveniles captured in summer and the corresponding adults captured in the preceding spring. $\Delta E d a\left[\right.$ reproductive investment] is the difference in $E d a^{\mathrm{L}}$ frequency in spring between individuals that did and did not visibly invest in reproduction. $\Delta E d a$ [overwinter survival] is the difference in $E d a^{\mathrm{L}}$ frequency between adults captured in spring vs. subadults captured in the preceding fall. (a) Salinity vs. $\Delta E d a[$ reproductive output]; (b) $\Delta E d a[$ reproductive investment] vs. $\Delta E d a[$ reproductive output]; (c) Distance to the coast vs. $\Delta E d a[$ reproductive output]; (d) Salinity vs. $\Delta E d a$ [overwinter survival]; (e) $\mathrm{pH}$ vs. $\Delta E d a$ [overwinter survival]; (f) Distance to the coast vs. $\Delta E d a$ [overwinter survival]. 


\section{Selection vs. gene flow}

While the Lositan analysis classified the Eda-linked marker STN380 as a locus putatively under divergent selection $\left(F_{\mathrm{ST}}[E d a]=0.115 ; P=0.008\right)$, BAYESCAN did not $(P=0.9642)$. The global $P_{\mathrm{ST}}$ value $\left(P_{\mathrm{ST}}=0.15\right)$ exceeded neutral $F_{\mathrm{ST}}\left(F_{\mathrm{ST}}=0.046,95 \% \mathrm{CI}=0.042-0.052\right)$, suggesting a contribution of divergent selection to phenotypic differentiation.

Among all habitat characteristics, only salinity was marginally correlated with $E d a^{\mathrm{L}}$ frequency and mean plate number. The $E d a^{\mathrm{L}}$ frequency decreased with salinity $(R=-0.50, P=0.0549$, Fig. $4 a)$, while mean plate number increased with salinity $(R=0.52, P=0.0484$, Fig. $4 b)$. However, in both cases, the correlation with allelic richness was stronger $\left(E d a^{\mathrm{L}}\right.$ frequency: $R=-0.72, \quad P=0.0035$, Fig. $4 \mathrm{c}$; mean plate number: $R=0.62, P=0.0190$, Fig. 4 d), as was the correlations with population-specific $F_{\mathrm{ST}}:(R=0.65, \quad P=0.0126$; mean plate number: $R=-0.54, P=0.0459)$. Multiple regressions followed by AICc-based model selection confirmed that $\mathrm{AR}$ and $F_{\mathrm{ST}}$ were better predictors of the $E d a$ allele frequency than salinity (i.e. all $\Delta \mathrm{AIC}_{\mathrm{C}}>2$; results not shown). This was also the case for plate number, except for $F_{\mathrm{ST}}$ vs. salinity, showing about equal effects (i.e. $\triangle \mathrm{AIC}_{\mathrm{C}}<2$ ).

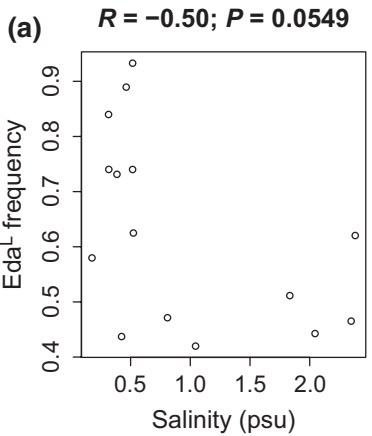

(c)

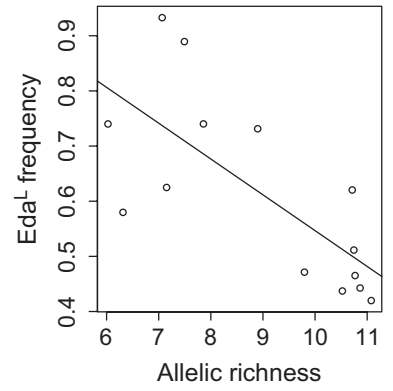

(b)

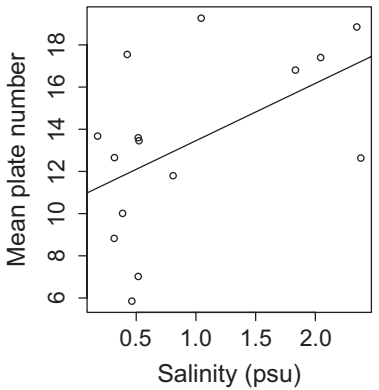

(d)

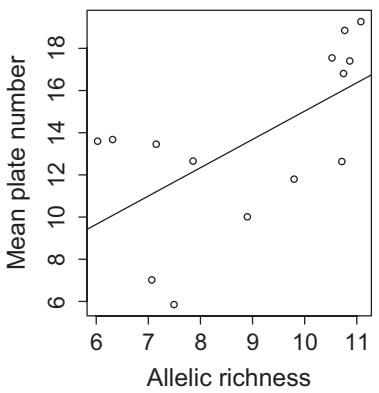

A similar pattern emerged from the analysis of pairwise $F_{\mathrm{ST}}[E d a]$ and pairwise $P_{\mathrm{ST}}$ for plate number. Pairwise $F_{\mathrm{ST}}[E d a]$ was not correlated with pairwise differential salinity $(R=0.003, P=0.43$; Fig. 4e), but significantly increased with neutral pairwise $F_{\mathrm{ST}}(R=0.42$; $P=0.009$; Fig. 4g). Likewise, pairwise $P_{\mathrm{ST}}$ for plate number did not increase with pairwise differential salinity $(R=0.079, P=0.27$; Fig. $4 \mathrm{f})$, but was marginally correlated with neutral pairwise $F_{\mathrm{ST}} \quad(R=0.28$; $P=0.064$; Fig. 4h). Partial Mantel tests revealed that the increase in pairwise $F_{\mathrm{ST}}[E d a]$ with neutral pairwise $F_{\mathrm{ST}}$ remained significant after correction for any habitat characteristic (results not shown). Figure 4G, H shows that $P_{\mathrm{ST}}$ for plate number and $F_{\mathrm{ST}}[E d a]$ remained low in the face of high gene flow (neutral $F_{\mathrm{ST}}<0.02$; this included all population pairs from site L01 to L07).

\section{Meta-analysis}

The LOSITAN and BAYESCAN outlier analyses always classified the Eda-linked markers as loci putatively under divergent selection, except for the lowland data set (i.e. the current study) for the analysis with BAYESCAN (Table 2; Fig. S4, Supporting information). Overall $P_{\mathrm{ST}}$ for plate number always significantly exceeded the
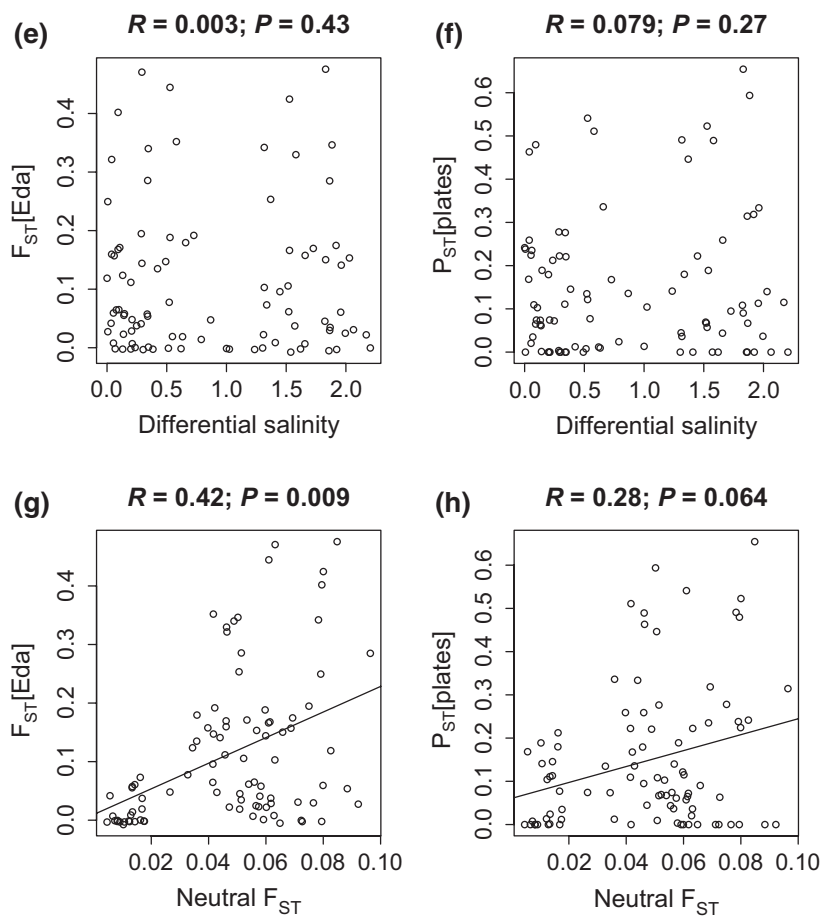

Fig. 4 Associations between neutral genetic diversity, salinity, the Eda locus and plate number in polymorphic stickleback populations from the Belgian-Dutch lowlands. (a) $E d a^{\mathrm{L}}$ frequency vs. salinity. (b) Mean plate number vs. salinity. (c) $E d a^{\mathrm{L}}$ frequency vs. allelic richness at neutral markers. (d) Mean plate number vs. allelic richness at neutral markers. (e) Pairwise $F_{\mathrm{ST}}[E d a]$ vs. pairwise differential salinity. (f) Pairwise $P_{\mathrm{ST}}$ for lateral plate number vs. pairwise differential salinity. (g) Pairwise $F_{\mathrm{ST}}[E d a]$ vs. neutral pairwise $F_{\mathrm{ST}}$. (h) Pairwise $P_{\mathrm{ST}}$ for lateral plate number vs. neutral pairwise $F_{\mathrm{ST}}$. 
neutral genetic differentiation (Table 2; distribution of plate number in each study system is provided in Fig. S5, Supporting information). The relationship between overall neutral $F_{\mathrm{ST}}$ and overall $F_{\mathrm{ST}}[E d a]$ across studies was positive ( $R=0.93, P=0.0078$, Fig. 5$)$. This was also the case for the relationship between overall neutral $F_{\mathrm{ST}}$ and overall $P_{\mathrm{ST}}$ for plate number $(R=0.93, P=0.0198$, Fig. 5). The current study deviated from these overall trends by having lower overall $F_{\mathrm{ST}}[E d a]$ and $P_{\mathrm{ST}}$ than predicted by the overall neutral $F_{\mathrm{ST}}$, hence having the lowest ratio of $F_{\mathrm{ST}}[E d a]$ vs. neutral $F_{\mathrm{ST}}$ and the lowest ratio of $P_{\mathrm{ST}}$ vs. neutral $F_{\mathrm{ST}}$.

The correlation between neutral genetic diversity and mean plate number was positive or nonsignificant, while the correlation between neutral genetic diversity and the $E d a^{\mathrm{L}}$ frequency was negative or nonsignificant (Table 2; Fig. S6, Supporting information). Correlations between neutral pairwise $F_{\mathrm{ST}}$ and pairwise $F_{\mathrm{ST}}[E d a]$ and pairwise $P_{\mathrm{ST}}$ for plate number were always nonsignificant, except for the current study where the correlation between neutral $F_{\mathrm{ST}}$ and $F_{\mathrm{ST}}$ [Eda] was positive (Table 2; Fig. S7, Supporting information). Interestingly, the Baltic system was characterized by $F_{\mathrm{ST}}[E d a]$ and $P_{\mathrm{ST}}$ values similar to the current study system, despite stronger neutral gene flow (Fig. 5). Accordingly, correlations between salinity and pairwise $F_{\mathrm{ST}}[E d a]$ or pairwise $P_{\mathrm{ST}}$ for plate number in the Baltic system (salinity vs. $F_{\mathrm{ST}}[E d a]: R=0.30, P=0.09$; salinity vs. $P_{\mathrm{ST}}: R=0.28$, $P=0.01$ ) were stronger than in the current study (salinity vs. $F_{\mathrm{ST}}[E d a]: R=0.003, P=0.43$; salinity vs. $P_{\mathrm{ST}}$ : $R=0.08, P=0.27$; Fig. 6).

\section{Discussion}

The aim of this study was to elucidate the relative contribution of divergent selection vs. homogenizing gene flow to allelic variation at a gene with major effects on an ecologically relevant trait. A classical example of such a gene is the Ectodysplasin (Eda) gene, the major gene controlling lateral plate phenotype in three-spined sticklebacks. We tracked the allele frequencies at this locus as well as at a set of neutral loci in 15 populations polymorphic for lateral plate number. Assessing the effect of divergent selection and gene flow at both the phenotypic and genetic level was relevant, because Eda accounts for more than $75 \%$ of the variation in the phenotype (Colosimo et al. 2004). Various studies have investigated adaptive polymorphisms in relationship to local selection and dispersal or gene flow. Examples include the PGI gene in Colias and Melitaea butterflies (Watt et al. 2003; Haag et al. 2005), haemoglobin in yellow-billed pintails (McCracken et al. 2009), MHC class IIb genes in lake and stream three-spined sticklebacks (Wegner et al. 2003), the rhodopsin gene in sand goby (Larmuseau et al. 2009) and pigmentation genes in pocket mice (Hoekstra et al. 2004).

The relative strength of divergent selection vs. opposing gene flow provides a general explanation for why populations may or may not diverge (Levene 1953; Endler 1973), and this has also been considered in sticklebacks (Hagen 1967; Bell 1982; Moore et al. 2007; Hendry et al. 2009). As such, it represents an important element in the ongoing discussion on the degree of parallelism in stickleback evolution (Berner et al. 2010; Jones et al. 2012; Ravinet et al. 2013). Below we discuss indications in our study system for divergent selection on the one hand and for the homogenizing effect of gene flow on the other hand.

\section{Indications for divergent selection}

Several experiments have revealed a differential selective advantage for the different plate morphs as well as for the allelic variants of the Eda gene. These differences were observed in response to either the abiotic environment (salinity) or to predation. With respect to salinity, Heuts (1947) observed that completely plated sticklebacks hatch more successfully in saltwater, whereas
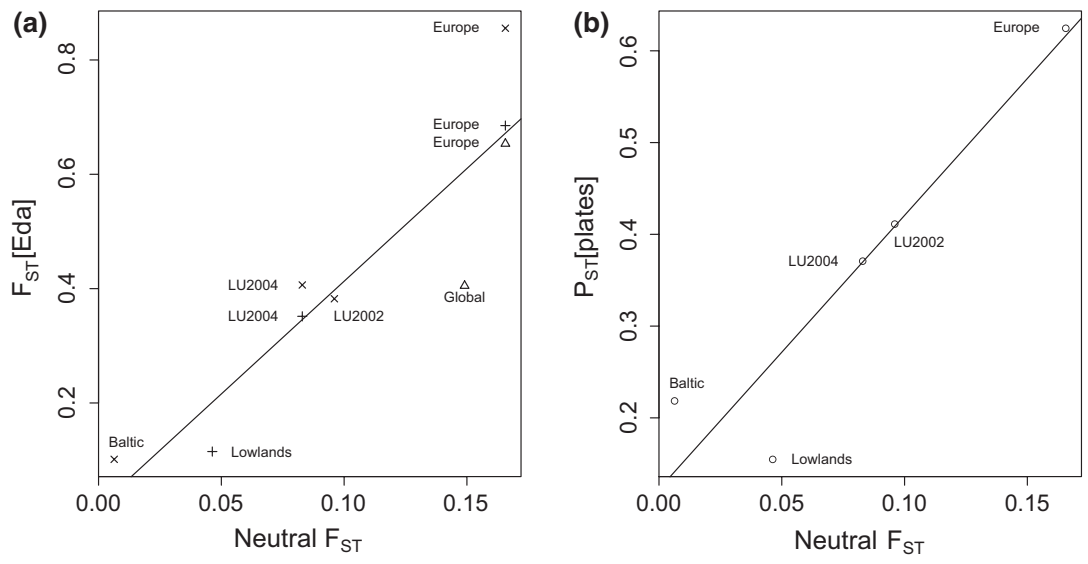

Fig. 5 Meta-analysis across six population genetic studies of three-spined stickleback. (a) Relationship between overall neutral $F_{\mathrm{ST}}$ and overall $F_{\mathrm{ST}}[E d a]$. The symbols indicate the different $E d a$-linked markers $(\Delta$, STN365; +, STN380; $\times$, STN381). (b) Relationship between overall neutral $F_{\mathrm{ST}}$ and overall $P_{\mathrm{ST}}$ for lateral plate number. Study systems are labelled as in Table 2 . 
(a)

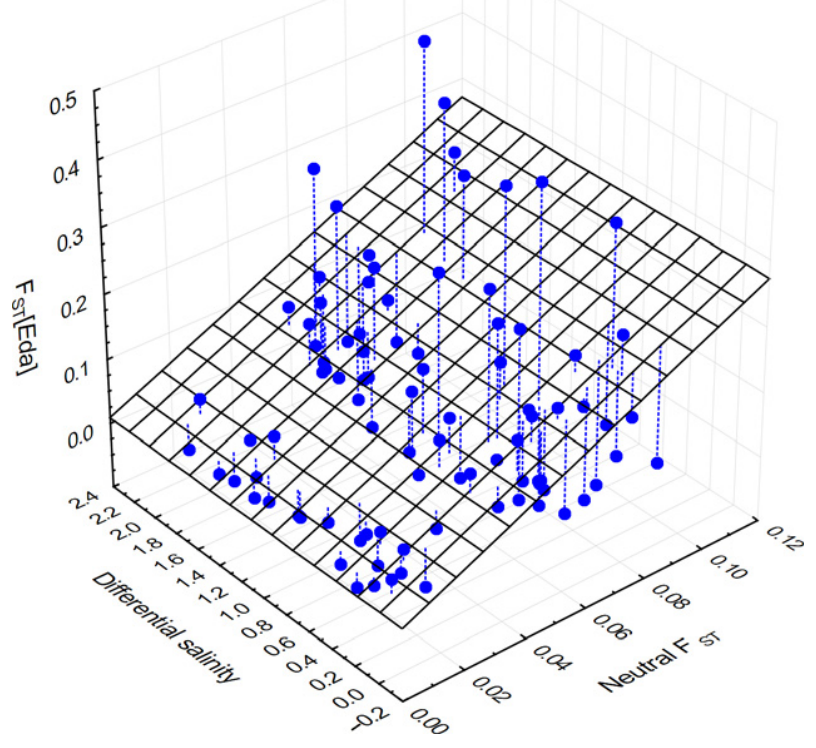

(c)

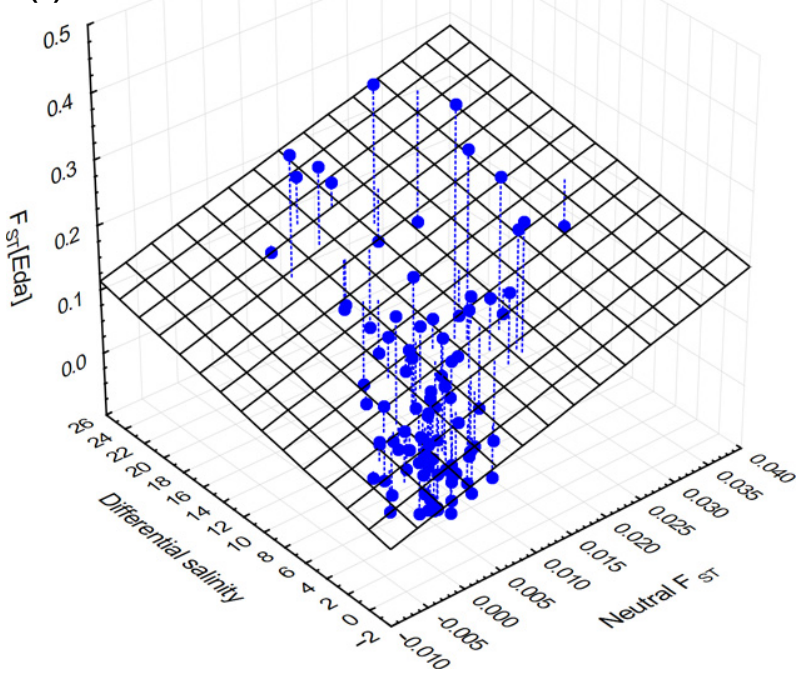

(b)

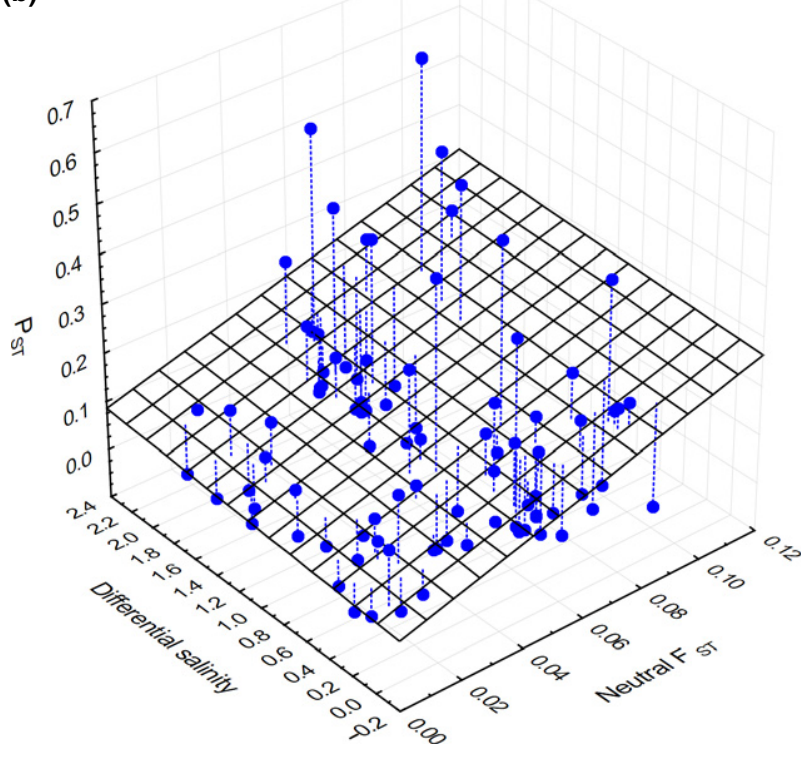

(d)

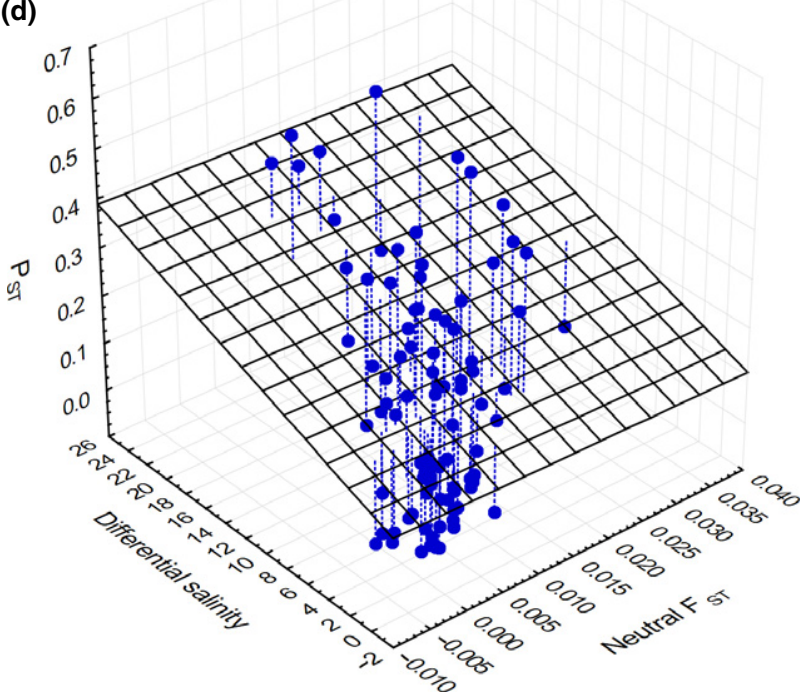

Fig. 6 Comparison of the lowland study system from Belgium and the Netherlands (current study) with the Baltic study system (DeFaveri \& Merilä 2013). (a) Pairwise $F_{\mathrm{ST}}[E d a]$ vs. neutral pairwise $F_{\mathrm{ST}}$ and pairwise differential salinity in the current study. (b) Pairwise $P_{\mathrm{ST}}$ for lateral plate number vs. neutral pairwise $F_{\mathrm{ST}}$ and pairwise differential salinity in the current study. (c) Pairwise $F_{\mathrm{ST}}$ [Eda] vs. neutral pairwise $F_{\mathrm{ST}}$ and pairwise differential salinity in the Baltic study system. (d) Pairwise $P_{\mathrm{ST}}$ for lateral plate number vs. neutral pairwise $F_{\mathrm{ST}}$ and pairwise differential salinity in the Baltic study system.

low-plated sticklebacks hatch more successfully in freshwater. Marchinko \& Schluter (2007) found that low-plated sticklebacks grow faster in freshwater than completely plated sticklebacks, whereas there was no such difference in saltwater. Barrett et al. (2008) found that fish carrying the $E d a^{\mathrm{L}}$ allele gain a growth advantage in freshwater, leading to higher overwinter survival and reproductive success. Barrett et al. (2009) found that this growth advantage is due to a pleiotropic effect of the Eda gene on armour and growth. With respect to predation, Reimchen (2000) demonstrated that completely plated sticklebacks have an advantage expressed as increased protection and escape opportunities. Leinonen et al. (2011) confirmed Reimchen's hypothesis that this advantage is habitat dependent, as in the presence of a refuge low-plated sticklebacks are 
more probably to escape from predatory fish than completely plated sticklebacks. Finally, Marchinko (2009) observed increased survival for individuals carrying the $E d a^{\mathrm{L}}$ allele in response to macro-invertebrate predation, whereas Zeller et al. (2012a) did not.

In this study, a differential selective advantage at the Eda gene was suggested when comparing subsequent generations. The Eda allele frequencies of juveniles in summer vs. representatives of the parental generation in the preceding spring showed a shift towards lower plate number in freshwater and a shift towards higher plate number in brackish (and more alkine) water. This shift from one generation to the next was significantly correlated with the differences in Eda allele frequency between adults who visibly invested in reproduction vs. adults that did not. Therefore, this pattern is probably indicative for greater (or earlier) reproductive success of individuals carrying the $E d a^{\mathrm{L}}$ allele in freshwater (i.e. similar to findings in Barrett et al. 2008) and of individuals carrying the $E d a^{C}$ allele in brackish water. However, we cannot attribute these differences in reproductive success to a growth advantage, as we did not observe significant differences in body size between the Eda genotypes at any life stage. We also cannot confirm a role for predation, as neither Eda allele frequencies nor changes in Eda allele frequencies were correlated with the density of macro-invertebrate predators.

\section{Indications for the homogenizing effect of gene flow}

Despite the indications for divergent selection in response to salinity levels from one generation to the next, salinity was only marginally correlated with the variation at the Eda locus and variation in plate number in our field survey. Likewise, pairwise differentiation at the Eda gene and pairwise $P_{\mathrm{ST}}$ for plate number did not correlate with pairwise differential salinity. The main reason for this lack of correlation was that the populations at some of the brackish sites still included a considerable fraction of low-plated individuals (e.g. L04), while populations at some of the freshwater sites still included a considerable fraction of completely plated individuals (e.g. L07). Relatively weak correlations between plate number and salinity or conductivity have been reported in other studies (Hagen \& Gilbertson 1972; DeFaveri \& Merilä 2013). While this suggests that salinity might not be the main selective agent for plate number, we did not observe strong correlations with other environmental cues either. Admittedly, our environmental assessment was not exhaustive, and other factors influencing the selective advantage of Eda genotypes have been proposed, such as calcium concentrations (Giles 1983).
Remarkably, however, variation in plate number and allelic variation at the Eda locus was strongly correlated with neutral population structure. Neutral genetic diversity outperformed salinity as a predictor of Eda allele frequency and mean plate number. Pairwise differentiation at the Eda locus increased with pairwise neutral $F_{\mathrm{ST}}$ and remained low in contrasts between populations characterized by low $F_{\mathrm{ST}}$ values, indicating substantial gene flow. There are two potential explanations for these correlations. First, adaptive divergence at the Eda locus due to a strong environmental cue might constrain gene flow between divergent populations (i.e. isolation by adaptation; Funk et al. 2011). If so, we clearly failed to document such environmental cue. However, if present, it would probably be correlated with distance to the coast (indicative for the declining influence of the coastal environment), which was also a strong predictor of plate number and Eda allele frequency. Second, high gene flow might constrain adaptive divergence by homogenizing allele frequencies at the Eda locus. This possibility seems more likely. It is known that some completely plated stickleback populations are anadromous, performing spawning migrations from coastal to freshwater habitats after a substantial raise in water temperature in spring (Wootton 1976). Such behaviour has also been reported in our study area (Tudorache et al. 2007). At least part of our freshwater populations might hence be exposed to high levels of gene flow from such anadromous populations, counteracting selection by a new influx of maladaptive or subadaptive alleles. Another indication that dispersal and gene flow are substantial in the lowlands is the fast recolonization of ditches and streams after summer droughts (personal observation).

The adaptive significance of variation in lateral plate phenotypes has received much attention since the observation that lateral plates might be targeted by selection (Hagen \& Gilbertson 1973). In contrast, the possibility of gene flow counteracting selection on lateral plate phenotypes has been rarely tested. In a study of clinal variation for the number of lateral plates within the low-plated morph across a stream gradient, Bell \& Richkind (1981) concluded that gene flow must counter selection. Likewise, Baumgartner (1986) demonstrated that both selection and gene flow shape the distribution of plate morphs in two adjacent streams. Since the discovery of the major effect of the Eda gene on plate number (Colosimo et al. 2005), studies still focus on the role of selection, but genomic studies testing for signatures of selection at the Eda gene typically account for genome-wide differentiation, which is partially reflecting gene flow (e.g. Mäkinen et al. 2008; DeFaveri et al. 2011; DeFaveri \& Merilä 2013). A meta-analysis on six such studies provided further support for the 
homogenizing effect of gene flow in our study system. First, compared to the other stickleback systems, the signature of selection at Eda in this study was weak. Second, the lowland system was the only system where pairwise neutral $F_{\mathrm{ST}}$ correlated significantly with $F_{\mathrm{ST}}[E d a]$. Comparison with the Baltic system (DeFaveri \& Merilä 2013) revealed that divergence at the Eda locus is possible even in the face of stronger gene flow than in our study. The difference is probably due to a broader range of salinities or correlated environmental effects in the Baltic (saltwater to freshwater) than in this study (brackish to freshwater).

\section{Limitations and alternative explanations}

Anadromous migration by completely plated individuals provides a straightforward explanation for the persistence of individuals carrying the $E d a^{\mathrm{C}}$ allele in freshwater despite counteracting selection. However, one limitation of our study is that we did not find direct indications for migration load. Although this might be due to the lack of power to quantify migration using molecular markers, it is possible that anadromous populations are uncommon or only occur locally. Alternatively, it might be that anadromous and resident freshwater populations interbreed infrequently (Hagen 1967; Jones et al. 2006; Bell et al. 2010) and hence that substantial gene flow is only realized over several generations. The persistence of individuals carrying the $E d a^{\mathrm{L}}$ allele in brackish water despite counteracting selection suggests that gene flow is also important in the opposite direction. Gene flow from freshwater to resident brackish water and marine stickleback might again be facilitated by anadromous populations. Such introgression contributes to the retention of freshwateradapted alleles in marine populations, which facilitates the evolutionary response to directional selection after freshwater colonization. This process is referred to as 'allelic recycling' (Schluter \& Conte 2009; Bell \& Aguirre 2013).

Alternative explanations of why populations might remain polymorphic for plate number include time since divergence, genetic constraints, relaxation of selection, environmental heterogeneity and balancing selection. Time since divergence explained the decline in plate number in Norwegian lakes which underwent isolation through gradual uplifting from sea level after deglaciation (Klepaker 1995). The position of the coastline in our study area has been shifting since the Holocene, and the current transgression was stabilized only 500 years ago as a result of human activities. Therefore, some of our study sites certainly escaped earlier from marine influence than others. Nevertheless, it is likely that all study sites have been interconnected for most of the time and therefore never experienced long periods of isolation. Moreover, it is known that completely plated populations can evolve towards almost 100\% low platedness in less than two decades (Bell \& Aguirre 2013).

Genetic constraints on the Eda gene making the gene less susceptible for selection than elsewhere, including different epistatic or pleiotropic fitness effects, are unlikely, given that monomorphic low-plated and monomorphic completely plated populations do occur further inland (Heuts 1947; Raeymaekers et al. 2008, 2009) and further north in the North Sea (Jones et al. 2006), respectively. Relaxation of selection is also an unlikely explanation for the maintenance of plate number polymorphism, given the indications for differential selective advantages at the Eda gene (see above). An important contribution of environmental heterogeneity is also unlikely as we found that habitat characteristics, in particular salinity, differed between sites and were relatively stable during the course of the study.

One possibility we cannot rule out at this stage is balancing selection. For instance, Barrett et al. (2008) observed indications for opposing selection at the Eda gene during different life stages, suggesting either that the Eda gene affects additional traits undergoing selection, or that linked loci are also affecting fitness. Genomic studies have pointed out that the Eda gene is contained within a large block of genes in ancient and stable linkage, increasing the potential for pleiotropic effects (Colosimo et al. 2005; Albert et al. 2008; Jones et al. 2012). For the current study, the shifts from fall to spring (i.e. $\Delta E d a$ [overwinter survival]) were opposite to those from spring to summer (i.e. $\Delta E d a[$ reproductive output]; Fig. 3), and this might in principle reflect opposing selection rather than a migration-selection balance. Nevertheless, such complex selection conditions are unlikely to generate the observed pattern of plate number declining with distance from the coast and its strong correlation with neutral genetic diversity.

\section{Conclusion and implications}

Our findings suggest that polymorphism and geographical variation for lateral plate number in the lowland stickleback populations from North-western Europe are maintained through a combination of divergent selection targeting the Eda gene and homogenizing gene flow. As a result, these populations were characterized by the lowest ratio of $F_{\mathrm{ST}}$ at the Eda gene vs. neutral $F_{\mathrm{ST}}$ in comparison with other stickleback systems, investigated across similar environmental gradients.

It has been hypothesized that the parallel evolution of freshwater phenotypes across the stickleback's distribution range is facilitated by standing variation in 
marine populations, composed of genes which have been 'recycled' from freshwater to marine populations (Schluter \& Conte 2009). Such a recycling mechanism requires substantial introgression between marine and freshwater populations, which is hindered by the high effective population size of the marine populations (Bell \& Aguirre 2013). We here documented that substantial gene flow can act as one potential source of incomplete phenotypic parallelisms upon freshwater colonization. However, the presence of such high gene flow areas also implies that freshwater alleles might frequently exchange between freshwater and brackish water populations, which ultimately might speed up the recycling of freshwater alleles into marine populations.

Our study highlights how allele frequencies at ecologically relevant genes are shaped by the relative strength of selection and gene flow and shows that such genes do not always contribute much to local adaptation. This also implies that ecologically relevant genes are not always detectable with standard outlier tests, even when selection on these genes is detectable as an ongoing process.

\section{Acknowledgements}

We thank Anneleen Van Geystelen, Dorien Verheyen, Koen Martens, Sanne Ruyts, Kathelijne Szekér, Sarah Tilkin, Jo-Ann De Roos, Tina Van den Meersche, Sarah Geldof, Nicolas Thiercelin, Io Verdonck, Lize Jacquemin, Nele Boon and Frank Spikmans (RAVON) for field support and technical assistance. We also thank Rowann Barrett, Gregory Maes, Eveline Diopere, Michael Bell and two anonymous reviewers for insightful and inspiring comments. Jacquelin DeFaveri, Takahito Shikano, Hannu Mäkinen, Tuomas Leinonen and Juha Merilä kindly provided data for the meta-analysis. Research was sponsored by the Research Foundation - Flanders (project G.0142.03, research community W0.037.10N 'Eco-evolutionary dynamics in natural and anthropogenic communities', and post-doctoral fellowship to M.H.D.L) and the University of Leuven (KU Leuven Centre of Excellence PF/10/07). J.A.M.R received a EU Marie Curie Fellowship (IEF 300256).

\section{References}

Albert AYK, Sawaya S, Vines TH et al. (2008) The genetics of adaptive shape shift in stickleback: pleiotropy and effect size. Evolution, 62, 76-85.

Antao T, Lopes A, Lopes RJ, Beja-Pereira A, Luikart G (2008) LOSITAN: a workbench to detect molecular adaptation based on a $\mathrm{F}_{\mathrm{ST}}$-outlier method. BMC Bioinformatics, 9, 323.

Banbura J (1994) Lateral plate morph differentiation of freshwater and marine populations of the three-pined stickleback, Gasterosteus aculeatus, in Poland. Journal of Fish Biology, 44, 773-783.

Barrett RDH (2010) Adaptive evolution of lateral plates in stickleback: a case study in functional analysis of natural variation. Journal of Fish Biology, 77, 311-328.
Barrett RDH, Rogers SM, Schluter D (2008) Natural selection on a major armor gene in threespine stickleback. Science, 322, 255-257.

Barrett RDH, Rogers SM, Schluter D (2009) Environment specific pleiotropy facilitates divergence at the Ectodysplasin locus in threespine stickleback. Evolution, 63, 2831-2837.

Baumgartner JV (1986) The genetics of differentiation in a stream population of the threespine stickleback, Gasterosteus aculeatus. Heredity, 57, 199-208.

Baumgartner JV, Bell MA (1984) Lateral plate morph variation in California populations of the threespine stickleback, Gasterosteus aculeatus. Evolution, 38, 665-674.

Bell MA (1982) Differentiation of adjacent stream populations of threespine sticklebacks. Evolution, 36, 189-199.

Bell MA (2001) Lateral plate evolution in the threespine stickleback: getting nowhere fast. Genetica, 112, 445-461.

Bell MA, Aguirre WE (2013) Contemporary evolution, allelic recycling, and adaptive radiation of the threespine stickleback. Evolutionary Ecology Research, 15, 377-411.

Bell MA, Richkind KE (1981) Clinal variation of lateral plates in threespine stickleback fish. American Naturalist, 117, 113-132.

Bell MA, Aguirre WE, Buck NJ (2004) Twelve years of contemporary armor evolution in a threespine stickleback population. Evolution, 58, 814-824.

Bell MA, Gangavalli AK, Bewick A, Aguirre WE (2010) Frequency of Ectodysplasin alleles and limited introgression between sympatric threespine stickleback populations. Environmental Biology of Fishes, 89, 189-198.

Berner D, Roesti M, Hendry AP, Salzburger W (2010) Constraints on speciation suggested by comparing lake-stream stickleback divergence across two continents. Molecular Ecology, 19, 4963-4978.

Brooks R (2002) Variation in female mate choice within guppy populations: population divergence, multiple ornaments and the maintenance of polymorphism. Genetica, 116, 343-358.

Colosimo PF, Peichel CL, Nereng K et al. (2004) The genetic architecture of parallel armor plate reduction in threespine sticklebacks. PLOS Biology, 2, 635-641.

Colosimo PF, Hosemann KE, Balabhadra S et al. (2005) Widespread parallel evolution in sticklebacks by repeated fixation of Ectodysplasin alleles. Science, 307, 1928-1933.

Cresko WA, Amores A, Wilson C et al. (2004) Parallel genetic basis for repeated evolution of armor loss in Alaskan threespine stickleback populations. Proceedings of the National Academy of Sciences of the United States of America, 101, 6050-6055.

DeFaveri J, Merilä J (2013) Evidence for adaptive phenotypic differentiation in Baltic Sea sticklebacks. Journal of Evolutionary Biology, 26, 1700-1715.

DeFaveri J, Shikano T, Shimada Y, Goto A, Merila J (2011) Global analysis of genes involved in freshwater adaptation in threespine sticklebacks (Gasterosteus aculeatus). Evolution, 65, 1800-1807.

Edelaar P, Bolnick DI (2012) Non-random gene flow: an underappreciated force in evolution and ecology. Trends in Ecology E Evolution, 27, 659-665.

Endler JA (1973) Gene flow and population differentiation. Science, 179, 243-250.

Endler JA (1977) Geographic Variation, Speciation, and Clines. Princeton University Press, Princeton, New Jersey.

Endler JA (1986) Natural Selection in the Wild. Princeton University Press, Princeton, New Jersey. 
Excoffier L, Laval G, Schneider S (2005) Arlequin ver. 3.0: an integrated software package for population genetics data analysis. Evolutionary Bioinformatics Online, 1, 47-50.

Foll M, Gaggiotti O (2006) Identifying the environmental factors that determine the genetic structure of populations. Genetics, 174, 875-891.

Foll M, Gaggiotti O (2008) A genome-scan method to identify selected loci appropriate for both dominant and codominant markers: a Bayesian perspective. Genetics, 180, 977-993.

Forsman A, Shine R (1995) The adaptive significance of color pattern polymorphism in the Australian scincid lizard Lampropholis delicata. Biological Journal of the Linnean Society, 55, 273-291.

Funk DJ, Egan SP, Nosil P (2011) Isolation by adaptation in Neochlamisus leaf beetles: host-related selection promotes neutral genomic divergence. Molecular Ecology, 20, 4671-4682.

García-Ramos G, Kirkpatrick M (1997) Genetic models of adaptation and gene flow in peripheral populations. Evolution, 51, $21-28$.

Giles N (1983) The possible role of environmental calcium levels during the evolution of phenotypic diversity in outer-Hebridean populations of the three-spined stickleback, Gasterosteus aculeatus. Journal of Zoology, 199, 535-544.

Haag CR, Saastamoinen M, Marden JH, Hanski I (2005) A candidate locus for variation in dispersal rate in a butterfly metapopulation. Proceedings of the Royal Society of London. Series B Biological Sciences, 272, 2449-2456.

Hagen DW (1967) Isolating mechanisms in threespine sticklebacks (Gasterosteus). Journal of the Fisheries Research Board of Canada, 24, 1637-1692.

Hagen DW, Gilbertson LG (1972) Geographic variation and environmental selection in Gasterosteus aculeatus L. in the Pacific Northwest, America. Evolution, 26, 32-51.

Hagen DW, Gilbertson LG (1973) Genetics of plate morphs in freshwater threespine sticklebacks. Heredity, 31, 75-84.

Hagen DW, Moodie GEE (1982) Polymorphism for plate morphs in Gasterosteus aculeatus on the east coast of Canada and an hypothesis for their global distribution. Canadian Journal of Zoology, 60, 1032-1042.

Hendry AP, Day T, Taylor EB (2001) Population mixing and the adaptive divergence of quantitative traits in discrete populations: a theoretical framework for empirical tests. Evolution, 55, 459-466.

Hendry AP, Bolnick DI, Berner D, Peichel CL (2009) Along the speciation continuum in sticklebacks. Journal of Fish Biology, 75, 2000-2036.

Heuts MJ (1947) Experimental studies on adaptive evolution in Gasterosteus aculeatus L. Evolution, 1, 89-102.

Hoekstra HE, Drumm KE, Nachman MW (2004) Ecological genetics of adaptive color polymorphism in pocket mice: geographic variation in selected and neutral genes. Evolution, 58, 1329-1341.

Jones FC, Brown C, Pemberton JM, Braithwaite VA (2006) Reproductive isolation in a threespine stickleback hybrid zone. Journal of Evolutionary Biology, 19, 1531-1544.

Jones FC, Grabherr MG, Chan YF et al. (2012) The genomic basis of adaptive evolution in threespine sticklebacks. Nature, 484, 55-61.

Joron M, Wynne IR, Lamas G, Mallet J (1999) Variable selection and the coexistence of multiple mimetic forms of the butterfly Heliconius numata. Evolutionary Ecology, 13, 721-754.
Kimura M (1983) The Neutral Theory of Molecular Evolution. Cambridge University Press, Cambridge, UK.

Kitano J, Bolnick DI, Beauchamp DA et al. (2008) Reverse evolution of armor plates in the threespine stickleback. Current Biology, 18, 769-774.

Klepaker T (1995) Postglacial evolution in lateral plate morphs in Norwegian freshwater populations of the threespine stickleback (Gasterosteus aculeatus). Canadian Journal of Zoology, 73, 898-906.

Klepaker T (1996) Lateral plate polymorphism in marine and estuarine populations of the threespine stickleback (Gasterosteus aculeatus) along the coast of Norway. Copeia, 1996, 832838 .

Kristjansson BK, Skulason S, Noakes DLG (2002) Rapid divergence in a recently isolated population of threespine stickleback (Gasterosteus aculeatus L.). Evolutionary Ecology Research, 4, 659-672.

Larmuseau MHD, Raeymaekers JAM, Ruddick KG, Van Houdt JKJ, Volckaert FAM (2009) To see in different seas: spatial variation in the rhodopsin gene of the sand goby (Pomatoschistus minutus). Molecular Ecology, 18, 4227-4239.

Larmuseau MHD, Vancampenhout K, Raeymaekers JAM, Van Houdt JKJ, Volckaert FAM (2010) Differential modes of selection on the rhodopsin gene in coastal Baltic and North Sea populations of the sand goby, Pomatoschistus minutus. Molecular Ecology, 19, 2256-2268.

Le Rouzic A, Østbye K, Klepaker TO et al. (2011) Strong and consistent natural selection associated with armor reduction in sticklebacks. Molecular Ecology, 20, 2483-2493.

Leinonen T, O'Hara RB, Cano JM, Merilä J (2008) Comparative studies of quantitative trait and neutral marker divergence: a meta-analysis. Journal of Evolutionary Biology, 21, 1-17.

Leinonen T, Herczeg G, Cano JM, Merilä J (2011) Predationimposed selection on threespine stickleback (Gasterosteus aculeatus) morphology: a test of the refuge use hypothesis. Evolution, 65, 2916-2926.

Leinonen T, McCairns RJS, Herczeg G, Merilä J (2012) Multiple evolutionary pathways to decreased lateral plate coverage in freshwater threespine sticklebacks. Evolution, 66, 3866-3875.

Lenormand T (2002) Gene flow and the limits to natural selection. Trends in Ecology \& Evolution, 17, 183-189.

Levene H (1953) Genetic equilibrium when more than one ecological niche is available. The American Naturalist, 87, 331-333.

Lucek K, Roy D, Bezault E, Sivasundar A, Seehausen O (2010) Hybridization between distant lineages increases adaptive variation during a biological invasion: stickleback in Switzerland. Molecular Ecology, 19, 3995-4011.

Lucek K, Haesler MP, Sivasundar A (2012) When phenotypes do not match genotypes-unexpected phenotypic diversity and potential environmental constraints in Icelandic stickleback. Journal of Heredity, 103, 579-584.

Mäkinen HS, Cano M, Merilä J (2008) Identifying footprints of directional and balancing selection in marine and freshwater three-spined stickleback (Gasterosteus aculeatus) populations. Molecular Ecology, 17, 3565-3582.

Marchinko KB (2009) Predation's role in repeated phenotypic and genetic divergence of armor in threespine stickleback. Evolution, 63, 127-138.

Marchinko KB, Schluter D (2007) Parallel evolution by correlated response: lateral plate reduction in threespine stickleback. Evolution, 61, 1084-1090. 
McCairns RJS, Bernatchez L (2008) Landscape genetic analyses reveal cryptic population structure and putative selection gradients in a large-scale estuarine environment. Molecular Ecology, 17, 3901-3916.

McCairns RJS, Bernatchez L (2012) Plasticity and heritability of morphological variation within and between parapatric stickleback demes. Journal of Evolutionary Biology, 25, 1097-1112.

McCracken KG, Bulgarella M, Johnson KP et al. (2009) Gene flow in the face of countervailing selection: adaptation to high-altitude hypoxia in the Beta A hemoglobin subunit of yellow-billed pintails in the Andes. Molecular Biology and Evolution, 26, 815-827.

McKinnon JS, Rundle HD (2002) Speciation in nature: the threespine stickleback model systems. Trends in Ecology $\mathcal{E}$ Evolution, 17, 480-488.

Merilaita S (2001) Habitat heterogeneity, predation and gene flow: colour polymorphism in the isopod, Idotea baltica. Evolutionary Ecology, 15, 103-116.

Moore JS, Gow JL, Taylor EB, Hendry AP (2007) Quantifying the constraining influence of gene flow on adaptive divergence in the lake-stream threespine stickleback system. Evolution, 61, 2015-2026.

Moser D, Roesti M, Berner D (2012) Repeated lake-stream divergence in stickleback life history within a central European lake basin. PLOS ONE, 7, e50620.

Münzing J (1963) The evolution of variation and distributional patterns in European populations of the three-spined stickleback, Gasterosteus aculeatus. Evolution, 17, 320-332.

van Oosterhout C, Hutchinson WF, Wills DPM, Shipley P (2004) Micro-Checker: software for identifying and correcting genotyping errors in microsatellite data. Molecular Ecology notes, 4, 535-538.

Peichel CL, Nereng KS, Ohgi KA et al. (2001) The genetic architecture of divergence between threespine stickleback species. Nature, 414, 901-905.

Pinho C, Hey J (2010) Divergence with gene flow: models and data. In: Annual Review of Ecology, Evolution, and Systematics, Vol 41(eds Futuyma DJ, Shafer HB \& Simberloff D), pp. 215230. Annual Reviews, Palo Alto, California.

Piry S, Alapetite A, Cornuet JM et al. (2004) Geneclass2: a software for genetic assignment and first-generation migrant detection. Journal of Heredity, 95, 536-539.

Pritchard JK, Stephens M, Donnelly P (2000) Inference of population structure using multilocus genotype data. Genetics, 155, 945-959.

R Core Team (2012) R: A Language and Environment for Statistical Computing. $\mathrm{R}$ Foundation for Statistical Computing. http://www.R-project.org/

Raeymaekers JAM, Maes GE, Audenaert E, Volckaert FAM (2005) Detecting Holocene divergence in the anadromousfreshwater three-spined stickleback (Gasterosteus aculeatus) system. Molecular Ecology, 14, 1001-1014.

Raeymaekers JAM, Van Houdt JKJ, Larmuseau MHD, Geldof S, Volckaert FAM (2007) Divergent selection as revealed by $\mathrm{P}_{\mathrm{ST}}$ and QTL-based $\mathrm{F}_{\mathrm{ST}}$ in three-spined stickleback (Gasterosteus aculeatus) populations along a coastal-inland gradient. Molecular Ecology, 16, 891-905.

Raeymaekers JAM, Maes GE, Geldof S et al. (2008) Modeling genetic connectivity in sticklebacks as a guideline for river restoration. Evolutionary Applications, 1, 475-488.
Raeymaekers JAM, Raeymaekers D, Koizumi I, Geldof S, Volckaert FAM (2009) Guidelines for restoring connectivity around water mills: a population genetic approach to the management of riverine fish. Journal of Applied Ecology, 46, 562-571.

Raeymaekers JAM, Lens L, Van den Broeck F, Van Dongen S, Volckaert FAM (2012) Quantifying population structure on short timescales. Molecular Ecology, 21, 3458-3473.

Rannala B, Mountain JL (1997) Detecting immigration by using multilocus genotypes. Proceedings of the National Academy of Sciences of the United States of America, 94, 9197-9201.

Räsänen K, Hendry AP (2008) Disentangling interactions between adaptive divergence and gene flow when ecology drives diversification. Ecology Letters, 11, 624-636.

Ravinet M, Prodohl PA, Harrod C (2013) Parallel and nonparallel ecological, morphological and genetic divergence in lake-stream stickleback from a single catchment. Journal of Evolutionary Biology, 26, 186-204.

Reimchen TE (2000) Predator handling failures of lateral plate morphs in Gasterosteus aculeatus: functional implications for the ancestral plate condition. Behaviour, 137, 1081-1096.

Schluter D (2000) The Ecology of Adaptive Radiation. Oxford University Press, Oxford.

Schluter D, Conte GL (2009) Genetics and ecological speciation. Proceedings of the National Academy of Sciences of the United States of America, 106, 9955-9962.

Slatkin M (1985) Gene flow in natural populations. Annual Review of Ecology and Systematics, 16, 393-430.

Taylor WR, Van Dyke GC (1985) Revised procedures for staining and clearing small fishes and other vertebrates for bone and cartilage study. Cybium, 9, 107-119.

Tudorache C, Blust R, De Boeck G (2007) Swimming capacity and energetics of migrating and non-migrating morphs of three-spined stickleback Gasterosteus aculeatus L. and their ecological implications. Journal of Fish Biology, 71, 1448-1456.

Van Dongen S, Lens L, Pape E, Volckaert FAM, Raeymaekers JAM (2009) Evolutionary history shapes the association between developmental instability and population-level genetic variation in three-spined sticklebacks. Journal of Evolutionary Biology, 22, 1695-1707.

Watt WB, Wheat CW, Meyer EH, Martin JF (2003) Adaptation at specific loci. VII. Natural selection, dispersal and the diversity of molecular-functional variation patterns among butterfly species complexes (Colias: Lepidoptera, Pieridae). Molecular Ecology, 12, 1265-1275.

Wegner KM, Reusch TBH, Kalbe M (2003) Multiple parasites are driving major histocompatibility complex polymorphism in the wild. Journal of Evolutionary Biology, 16, 224-232.

Wootton RJ (1976) The Biology of the Sticklebacks. Academic Press, London.

Zeller M, Lucek K, Haesler M, Seehausen O, Sivasundar A (2012a) Little evidence for a selective advantage of armour-reduced threespined stickleback individuals in an invertebrate predation experiment. Evolutionary Ecology, 26, 1293-1309.

Zeller M, Lucek K, Haesler MP, Seehausen O, Sivasundar A (2012b) Signals of predation-induced directional and disruptive selection in the threespine stickleback. Evolutionary Ecology Research, 14, 193-205.

Ziuganov VV (1983) Genetics of osteal plate polymorphism and microevolution of threespine stickleback (Gasterosteus aculeatus L.). Theoretical and Applied Genetics, 65, 239-246. 
J.A.M.R. designed and coordinated the study, analysed the data and wrote the study. N.K. assisted with fieldwork and genotyping. M.H.D.L. assisted with genotyping and data analysis, B.H. genotyped the samples, L.D.M. and F.A.M.V. supervised the research project. All co-authors participated in the conception of the study, revised it critically and approved the final version.

\section{Data accessibility}

Morphological and genetic data, geographical distances, habitat characteristics, data sets for meta-analysis: Dryad doi: doi:10.5061/dryad.d6620.

\section{Supporting information}

Additional supporting information may be found in the online version of this article.

Table S1 Schematic overview of analyses performed on 15 populations of three-spined stickleback from the Belgian and Dutch lowlands. Numbers correspond to sample sizes per Eda genotype (CC/CL/LL), sampled between spring 2008 and fall 2010.

Fig. S1 Classical multidimensional scaling plot of neutral population genetic structure among 59 stickleback samples, based on pairwise $F_{\mathrm{ST}}$. The samples belong to 14 populations that were sampled repeatedly (up to six times; see Table S1, Supporting information) between spring 2008 and fall 2010. Population L10 was excluded from the analysis.

Fig. S2 Frequency of the $E d a^{\mathrm{L}}$ allele in 15 polymorphic stickleback populations from Belgium and the Netherlands, sampled between spring 2008 and fall 2010. The A panel groups the data by season and uses different symbols and colours per site. A single sample from summer 2008 (site L07; see Table S1, Supporting information) was omitted. The B panel groups the data by site and uses different symbols per season. Vertical bars represent bootstrap-based standard errors.

Fig. S3 Body size as measured by standard length in (a) juveniles in summer $(N=793)$, (b) subadults in fall $(N=663)$ and (c) adults in spring $(N=484)$ in 15 stickleback populations from Belgium and the Netherlands. Blue, red and green symbols mark individuals that were homozygous for the $E d a^{\mathrm{C}}$ allele (CC), heterozygous (CL) or homozygous for the $E d a^{\mathrm{L}}$ allele (LL), respectively. Error bars represent 95\% confidence limits. None of the differences between the three genotypes were significant.

Fig. S4 Outlier test results using Lositan (left) and Bayescan (right) in six stickleback systems. The markers linked to the Eda gene are labelled (STN365, STN380 or STN381) and were all detected as markers under divergent selection, except for the test with Bayescan in the current study (i.e. the lowland study system). A false discovery rate of 0.05 was applied for both methods. Study systems are labelled as in Table 2 .

Fig. S5 Distribution of lateral plate number per locality in five stickleback systems. Localities are sorted from low to high average plate number. Horizontal bars represent standard errors. Study systems are labelled as in Table 2. The data represent one side of the fish only. For the data set from Europe (Mäkinen et al. 2008), the initial count considered both sides of the fish, and hence, the available numbers were divided by two. Keel plates were not included in the total count for the lowlands (current study), LU2002 (Raeymaekers et al. 2007) and LU2004 (Van Dongen et al. 2009) studies.

Fig. S6 $E d a^{\mathrm{L}}$ frequency vs. allelic richness at neutral markers (left), mean plate number vs. allelic richness at neutral markers (centre) and mean plate number vs. $E d a^{\mathrm{L}}$ frequency (right) in five stickleback systems. A linear regression line is drawn for significant relationships. Study systems are labelled as in Table 2.

Fig. S7 Pairwise $F_{\mathrm{ST}}[E d a]$ vs. neutral pairwise $F_{\mathrm{ST}}$ (left) and pairwise $P_{\mathrm{ST}}$ for lateral plate number vs. neutral pairwise $F_{\mathrm{ST}}$ (right) in six stickleback systems. As indicated by the linear regression line, only the correlation shown in the first plot was significant (pairwise $F_{\mathrm{ST}}[E d a]$ vs. neutral pairwise $F_{\mathrm{ST}}$ in the current study, i.e. the lowland study system). Study systems are labelled as in Table 2. 